\title{
Full-Scale 3-D Finite Element Modeling of a Two-Loop Pressurized Water Reactor for Heat Transfer, Thermal-Mechanical Cyclic Stress Analysis, and Environmental Fatigue Life Estimation
}

\author{
Subhasish Mohanty ${ }^{\dagger}$, William K. Soppet, Saurindranath Majumdar, and Krishnamurti Natesan \\ Argonne National Laboratory \\ Lemont, IL, USA
}

May 2015

\begin{abstract}
The submitted manuscript has been created by UChicago Argonne, LLC, Operator of Argonne National Laboratory ("Argonne"). Argonne, a U.S. Department of Energy

Office of Science laboratory, is operated under Contract No. DE-AC02-06CH11357. The

U.S. Government retains for itself, and others acting on its behalf, a paid-up nonexclusive, irrevocable worldwide license in said article to reproduce, prepare

derivative works, distribute copies to the public, and perform publicly and display

publicly, by or on behalf of the Government.
\end{abstract}

Paper for Submission to Journal of Nuclear Engineering and Design

*Work supported by U.S. DOE under Light Water Reactor Sustainability Program.

\footnotetext{
${ }^{\dagger}$ Corresponding author email: smohanty@anl.gov 


\title{
Full-Scale 3-D Finite Element Modeling of a Two-Loop Pressurized Water Reactor for Heat Transfer, Thermal-Mechanical Cyclic Stress Analysis, and Environmental Fatigue Modeling
}

\author{
Subhasish Mohanty ${ }^{\ddagger}$, William K. Soppet, Saurindranath Majumdar, and Krishnamurti Natesan \\ Argonne National Laboratory \\ Lemont, IL, USA
}

\begin{abstract}
This paper discusses a system-level finite element model of a two-loop pressurized water reactor (PWR). Based on this model, system-level heat transfer analysis and subsequent sequentially coupled thermal-mechanical stress analysis were performed for typical thermalmechanical fatigue cycles. The in-air fatigue lives of example components, such as the hot and cold legs, were estimated on the basis of stress analysis results, ASME in-air fatigue life estimation criteria, and fatigue design curves. Furthermore, environmental correction factors and associated PWR environment fatigue lives for the hot and cold legs were estimated by using estimated stress and strain histories and the approach described in US-NRC report: NUREG6909.
\end{abstract}

\section{Introduction}

System-level computer modeling of complex nuclear systems is increasingly becoming a trend due to the availability of advanced multi-physics computer programs and the increasing use of multiprocessor-based parallel computing hardware and software. Recently, many works have been published on thermal-hydraulics simulations of fluid flow and heat transfer in a single reactor component or in a complex large-scale assembly [1-7]. This type of system-level thermal-hydraulics model helps to better understand and to accurately predict the fluid flow and heat transfer not only in individual components but also the overall system and the interaction with each other. Along a similar line, computational structural mechanics analysis is increasingly being used to perform stress and fracture mechanics analysis under complex component/assembly-level multi-axial stress states. For example, recent advances in 3-D finite element analyses (FEA) code and associated improvements in multi-physics modeling capability (e.g., thermal-mechanical stress analysis) and fracture mechanics simulation capability allow more accurate 3-D stress and structural integrity analysis of reactor components not only under combined thermal-mechanical loading but also under multi-axial component/assembly-level stress states [8-10]. In addition to the above-mentioned multi-physics thermal-mechanical stress analysis, the present-generation FEA code also allows determination of the effect of other field variables, such as the effect of neutron dose on the $3 \mathrm{D}$ stress state of reactor structural components [11,12]. Furthermore, advances in FEA tools for 3-D fracture mechanics and crack propagation allow accurate prediction of the structural integrity of reactor components under severe accident conditions, such as loss-of-coolant accidents (LOCAs). For example,

\footnotetext{
${ }^{\ddagger}$ Corresponding author email: smohanty@anl.gov
} 
propagation of preexisting stress corrosion cracking (SCC) in steam generator tubes and the associated rupture pressure can be predicted accurately under LOCA [13]. Similarly, in reactor pressure vessels and other primary pressure boundary components, the effect of pressurized thermal shock (PTS) under severe accident conditions can be predicted by using 3-D FEA tools [14-19]. Both LOCA and PTS conditions are key elements in the integrity evaluation of nuclear reactor components and require a multidisciplinary effort to link the thermal-hydraulic analysis results to structural and fracture mechanics models. In addition to the multi-physics capability, the current-generation FEA code also allows one to model complex time-dependent material effects. For example, time-dependent creep damage of the reactor pressure vessel under severe accident conditions, such as a LOCA, can be more accurately predicted by using componentscale, 3-D FEA models [20].

The above-mentioned structural analysis examples based on FEA are mostly restricted to a single component under static or quasi-static transient loading. However, a few studies have been done involving thermal-mechanical fatigue modeling using system-level 3-D models. Also, at present, most of the work related to fatigue evaluation in reactor environments is based on stress analysis at the individual component level combined with estimation of the associated fatigue life using stress/strain life curves [21-24]. However, as part of the Light Water Reactor Sustainability (LWRS) program sponsored by the Department of Energy (DOE), Argonne National Laboratory (ANL) is trying to develop a more mechanistic-based fatigue evaluation approach $[25,26]$ under realistic multi-physics and multi-axial stress states. Under this program ANL is trying to develop an assembly level finite element (FE) model for system-level stress analysis and associated fatigue life evaluation under thermal-mechanical cyclic loading. For the purpose, in the present work, we developed preliminary FE models for a Westinghouse-type two-loop pressurized water reactor (PWR). Based on the FE models, system-level thermalmechanical fatigue (TMF) analyses were performed. Furthermore, these TMF results were used for in-air and environmental fatigue life estimation of some example components such as the reactor cold and hot legs. The related model and calculated results are discussed below.

\section{Finite Element Modelling}

\subsection{System level 3-D solid model}

Finite element models were developed for system-level TMF analysis of a typical two-loop PWR. The models were developed by using commercially available ABAQUS FE software [27]. The FE models were based on approximate geometry determined from publicly available literatures [28-32]. In the assembly-level model, only major reactor parts such as the pressure vessel, steam generator outer shell, and hot and cold leg pipes were considered. Figure 1 shows the resulting assembly-level 3-D solid model of the 2-loop PWR considered in this work. 


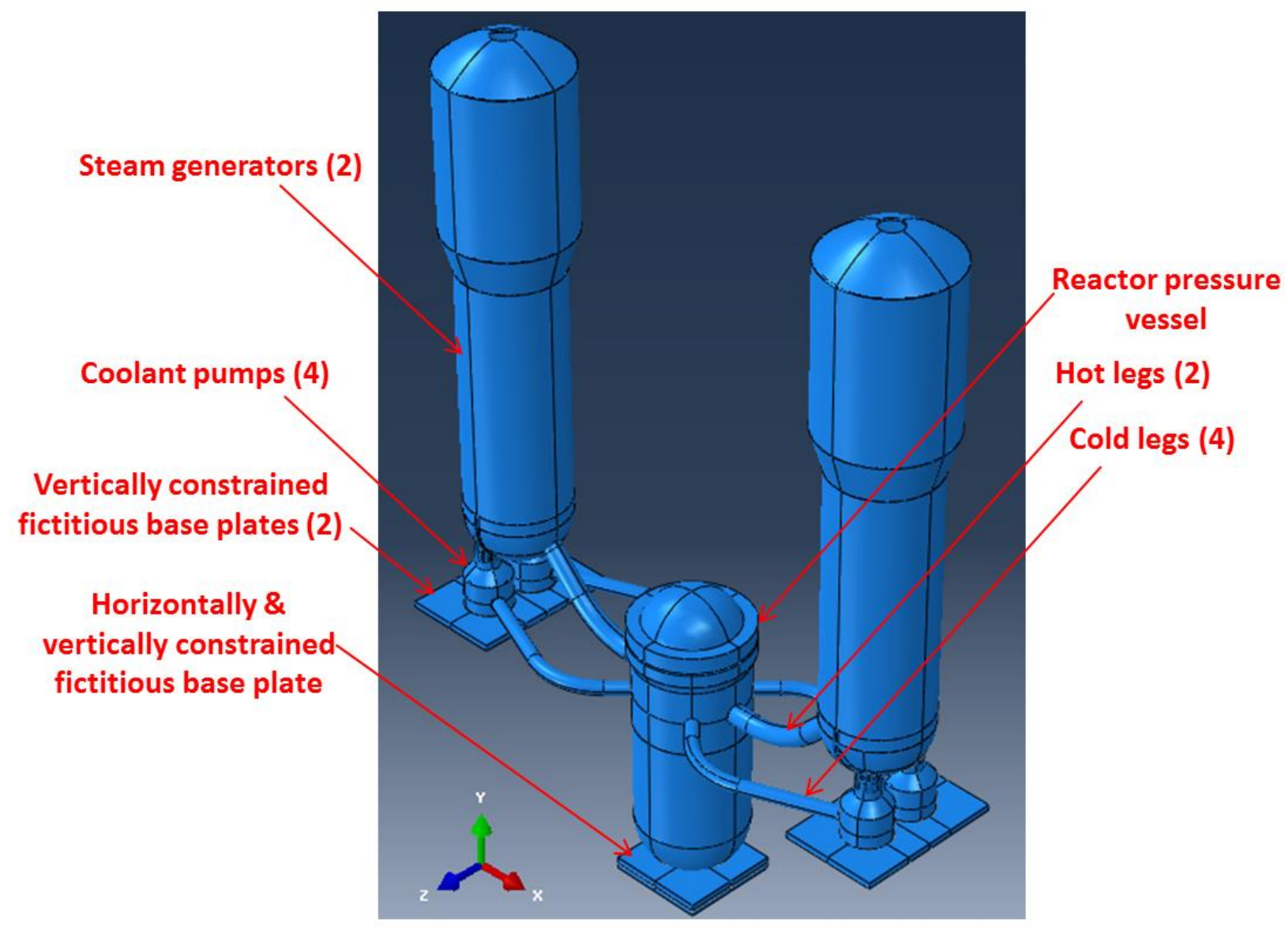

Figure 1 Assembly-level 3-D solid model of a two-loop PWR showing different component and boundary conditions.

For simplicity, the surge line and pressurizer were not considered in the assembly-level model. Also, a simplified coolant pump model was assumed, and only the top section that connects both the steam generator and cold leg was considered. However, in the future, for more detailed analysis, the surge line, pressurizer and other important components will be considered. The assembly-level model was developed by using 3-D solid models of individual components with single or multiple sections. The 3-D models were developed by using ABAQUS CAE software. The individual sections or components were appropriately constrained to maintain their locations with respect to the global assembly. In the assembly model, the individual sections were tied together by using tie constraints. The bottom section of the reactor pressure vessel (RPV) was tied to a base plate, which was attached to the ground and constrained in all directions. Similarly, the coolant pumps were tied to additional base plates. However, in contrast to the RPV base plates, the coolant pump base plates were only restricted in the vertical direction and were allowed to move along both horizontal directions. These constraints are shown in Figure 1. This condition was designed to mimic the real reactor conditions, allowing free thermal expansion. However, note that the above boundary conditions are simplified assumptions and do not necessarily represent the exact boundary conditions in a real reactor. For example in a typical 
Siemens designed PWR, the RPV is supported at its bottom end by an inverted frusto-conical surface concentric with the axis of the vessel and fixed to its bottom [33]. This surface rests on an upright frusto-conical surface which is also concentric with the vessel's axis. Radial thermal displacements of the RPV's bottom section results in diameter changes in the frusto-conical surface fixed to its bottom so that this surface by cam action slides up and down on the bottom frusto-conical surface. With a properly defined angularity between upper and bottom frustoconical surfaces, compensates the vertical thermal expansion of the vessel which occurs simultaneously with its radial expansion. In another example, for a Westinghouse designed reactor the main coolant flow nozzles (both hot and cold legs) serve as vessel supports in addition to performing their primary function as conduits [34]. The support nozzles rest on integral pads which allow free thermal expansion of RPV. However, in the work discussed in this paper, the details of the real reactor supports or boundary conditions were not considered, rather simplified boundary constraints for reactor supports were modeled as shown in Figure 1. In addition, in the present assembly-level model, we did not consider the plane of symmetries. In the future we intend to add unsymmetrical components such as a surge line and pressurizer, and it may not be possible to implement a symmetric boundary condition in the system-level reactor model. Hence, in the present model, symmetric boundary conditions were not considered for possible future amendment. The same assembly-level 3-D model was used for both heat transfer analysis and subsequent sequential structural analysis.

\subsection{Finite element mesh}

The individual components in the reactor assembly were FE meshed by using 3-D brick elements. We chose DC3D8, 8-node linear heat transfer elements to mesh the individual components in the assembly-level heat transfer models. The corresponding C3D8, 8-node linear elements were used for the stress analysis models. The assembly has a total of 85610 DC3D8 elements for heat transfer models or C3D8 elements for structural analysis models. Table 1 shows the number of elements and nodes used for individual components and the respective material type used in the simulation. Figure $2 \mathrm{a}$ shows the full assembly-level FE mesh of the considered 2-loop reactor. This figure also shows typical ID and OD surface elements. Figure 2b shows the magnified version of Figure 2a showing example elbow region mesh of HL, which element was considered for fatigue evaluation. Note that to lessen the computational burden, in the discussed assembly-level FE model, we only considered 2 elements along the thickness direction of each component. In addition, we had not studied the effect of mesh refinement on heat transfer and structural analysis results. In our future work, we will perform more detail analysis of individual components and with different level of mesh refinements to study the effect of mess sensitivity on FE results. The primary aim of the work presented in this paper was to develop an assembly level FE model, which results can be used as guidelines for the future component level detailed FE models. 
Table 1 Number of heat transfer or structural analysis finite elements in PWR assembly models

\begin{tabular}{|l|l|l|l|l|}
\hline $\begin{array}{l}\text { Component } \\
\text { name }\end{array}$ & $\begin{array}{l}\text { Total number of } \\
\text { components }\end{array}$ & Material type & $\begin{array}{l}\text { Total number of } \\
\text { DC3D8/C3D8 elements }\end{array}$ & $\begin{array}{l}\text { Total number of } \\
\text { nodes }\end{array}$ \\
\hline Pressure vessel & 1 & SA-508 (LAS) & 10806 & 16541 \\
\hline Steam generator & 2 & SA-508 (LAS) & $2 \times 19052=38104$ & $2 \times 28847=57694$ \\
\hline Hot leg pipe & 2 & SA-376 (SS) & $2 \times 2014=4028$ & $2 \times 3078=6156$ \\
\hline Cold leg pipe & 4 & SA-376 (SS) & $4 \times 3204=12816$ & $4 \times 4860=19440$ \\
\hline Coolant pump & 4 & SA-376 (SS) & $4 \times 4164=16656$ & $4 \times 6432=25728$ \\
\hline \begin{tabular}{l} 
RPV base plate \\
\hline
\end{tabular} & $\begin{array}{l}\text { Fictitious large } \\
\text { stiffness } \\
\text { material }\end{array}$ & 800 & 1764 \\
\hline $\begin{array}{l}\text { Coolant pump } \\
\text { base plate }\end{array}$ & 4 & $\begin{array}{l}\text { Fictitious large } \\
\text { stiffness } \\
\text { material }\end{array}$ & $4 \times 600=2400$ & $4 \times 1302=5208$ \\
\hline Total number of elements/nodes in assembly & 85610 & 132531 \\
\hline
\end{tabular}

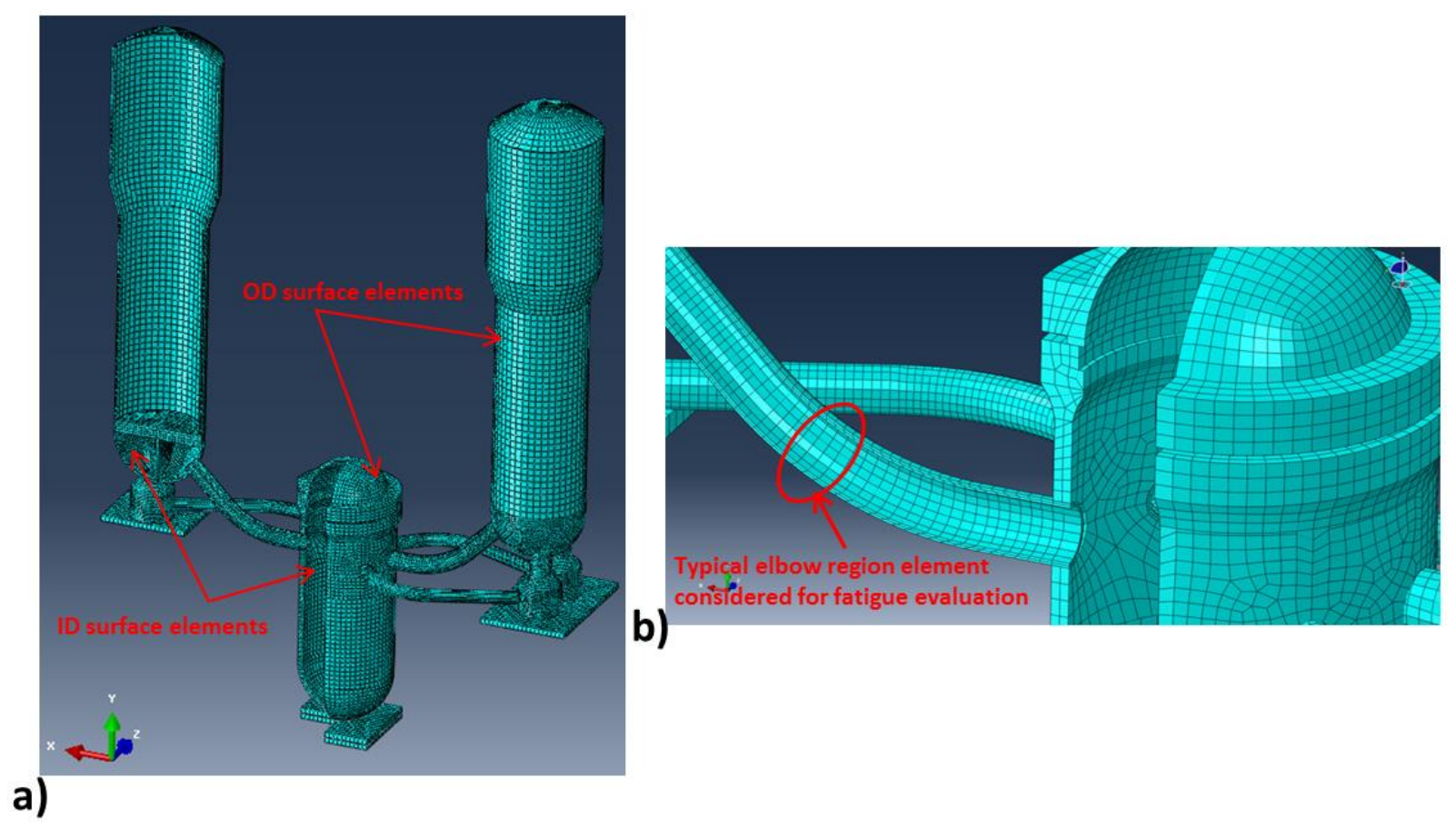

Figure 2 a) Full system-level FE mesh of two-loop PWR showing typical ID and OD surface elements b) Magnified mesh showing typical example elbow region mesh of HL, which element was considered for fatigue evaluation. 


\subsection{Heat transfer model}

An uncoupled heat transfer analysis was performed by multiple steps of transient heat transfer analysis. The heat transfer analysis was performed with ABAQUS software, for which the variational form of the governing energy balance equation can be given as [27]:

$$
\int_{V} \rho \dot{U} \delta \theta d V+\int_{V} \frac{\partial \delta \theta}{\partial x} \cdot k \cdot \frac{\delta \theta}{\partial x} d V=\int_{S} \delta \theta q d S
$$

where $\rho$ is density of material, $V$ is the volume of solid material with surface area $S$, and $q$ is the heat flux per unit area flowing into or out of the body. Also in Eq. 1, $U$ is the material internal energy, which can be expressed in terms of the temperature-dependent specific heat $c(\theta)$ as:

$$
c(\theta)=\frac{d U}{d \theta}
$$

The heat conduction is assumed to be governed by the Fourier law and can be expressed in terms of the temperature-dependent thermal conductivity $(\theta)$ :

$$
f=-k(\theta) \frac{\partial \theta}{\partial x}
$$

The surface heat flux $q$ in Eq. 1 can be expressed in terms of the temperature-dependent film coefficient $h(\theta)$ as:

$$
q=h(\theta)\left(\theta-\theta_{0}\right)
$$

In ABAQUS, we defined all the ID surface boundaries with time-dependent temperature sinks and the convective film condition. Two repetitive cycles were simulated each with four transient heat transfer steps. At the initial condition, all the material volumes were subjected to a temperature of $37.78{ }^{\circ} \mathrm{C}$. Before the start of cyclic heat transfer analysis, additional transient heat transfer analysis was performed to bring up/down the boundary condition temperature to the starting temperature of the first cycles. Nine heat transfer steps were performed over the entire simulation duration. During the first step, all the OD surfaces were defined with the ambient temperature boundary condition of $37.78^{\circ} \mathrm{C}$ and convective film condition. The convective film coefficient $h$ for the ambient convective film condition was assumed based on the mass fraction of non-condensable gas (air) versus heat transfer coefficient curve given in literature [35]. Assuming very low humidity inside the reactor containment due to the recirculation of air [36], and following the above mentioned curve, the approximate film coefficient $h$ for the ambient air was chosen as $100 \mathrm{~W} / \mathrm{m}^{2}-\mathrm{K}$. However, inside the RPV and other reactor coolant system components such as SG, HL, and CL temperature-dependent coolant water film coefficient was defined for all ID temperature boundary conditions. The highest temperature considered for the boundary condition was $315.56{ }^{\circ} \mathrm{C}$. The highest film coefficient corresponding to this temperature was assumed equal to $7155 \mathrm{~W} / \mathrm{m}^{2}-\mathrm{K}$. The basis for the selection of highest film coefficient is explained in section 3.1. Different ID surfaces were defined with different cyclic 
temperature boundary conditions. For the purpose, we used the temperature and pressure transients given in US-NRC report [21] and EPRI report [23]. The transients were used to make two temperature or pressure cycles. In between two temperature/pressure cycles, sufficient time was maintained to reduce the ID/OD temperature (simulated through heat transfer analysis) to its original temperature. Figure 3 shows the temperature and pressure cycles applied to the ID surface of the reactor pressure vessel and hot leg.

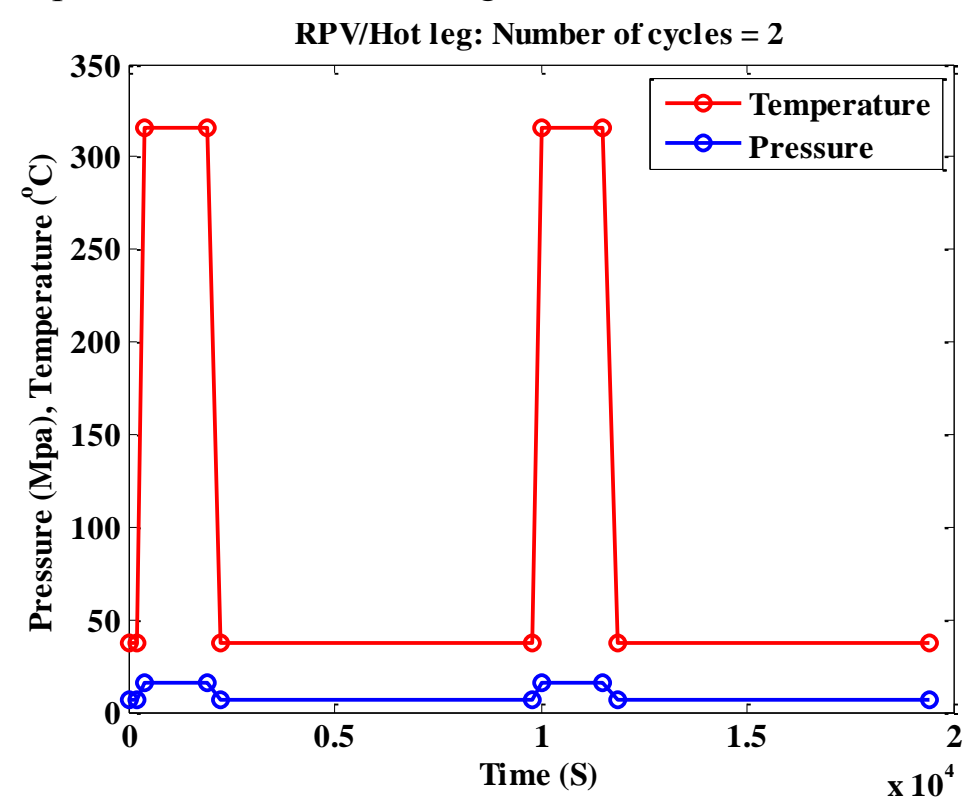

Figure 3 Temperature and pressure boundary conditions applied to the ID surfaces of RPV and hot leg

The temperature and pressure cycles shown in Figure 3 were scaled (normalized with respect to the maximum temperature of $315.56{ }^{\circ} \mathrm{C}$ ) to develop the time-dependent boundary temperature and pressure cycles for the ID surface of the cold leg, as well as the shell feed water section and shell steam section of the steam generator. For the purpose the maximum temperature on the ID surface of cold leg, steam generator feed water and steam section were respectively considered as $275{ }^{\circ} \mathrm{C}, 220{ }^{\circ} \mathrm{C}$ and $275{ }^{\circ} \mathrm{C}$. The maximum pressure for ID surfaces of RPV, hot leg, cold leg was considered equal to $15.513 \mathrm{MPa}$. Whereas the maxim pressure for SG shell feed water and steam section was considered equal to $7 \mathrm{MPa}$. Note that the temperature and pressure cycles were chosen to simulate typical reactor heat-up/cool-down cycles and do not necessarily represent actual reactor conditions. Table 2 gives the transient heat transfer step number and associated step time with respect to the applied boundary temperature for the RPV ID surface, and these data are for future reference in the later part of this report.

Table 2 Transient heat transfer step number and associated RPV ID temperature boundary conditions

\begin{tabular}{|l|l|l|l|l|l|l|l|l|l|}
\hline $\begin{array}{l}\text { Cycle no. } \\
(\rightarrow)\end{array}$ & 0 & \multicolumn{9}{|l|}{1} & \multicolumn{3}{l|}{} \\
\hline Step no. $(\downarrow)$ & 1 & 2 & 3 & 4 & 5 & 6 & 7 & 8 & 9 \\
\hline
\end{tabular}




\begin{tabular}{|l|l|l|l|l|l|l|l|l|l|}
\hline $\begin{array}{l}\text { End step } \\
\text { time (s) }\end{array}$ & 200 & 400 & 1,900 & 2,250 & 9,810 & 10,010 & 11,510 & 11,860 & 19,420 \\
\hline $\begin{array}{l}\text { Start temp. } \\
\left({ }^{\circ} \mathrm{C}\right)\end{array}$ & 37.78 & 37.78 & 315.56 & 315.56 & 37.78 & 37.78 & 315.56 & 315.56 & 37.78 \\
\hline $\begin{array}{l}\text { End temp. } \\
\left({ }^{\circ} \mathrm{C}\right)\end{array}$ & 37.78 & 315.56 & 315.56 & 37.78 & 37.78 & 315.56 & 315.56 & 37.78 & 37.78 \\
\hline
\end{tabular}

\subsection{Structural analysis cases}

The structural analyses were performed for the following cases:

a) Only cyclic pressure (P)

b) Only cyclic temperature $(\theta)$

c) Both cyclic pressure and temperature $(\mathrm{P}+\theta)$

The structural analysis cases under pure temperature or pure pressure loading were used to assess the contribution of individual temperature and pressure loading on overall stress analysis results performed under combined temperature and pressure loading. For the each three cases, nine stress analyses steps were performed to model the ID boundary temperature and pressure cycles (shown in Figures 3 and as discussed above). For stress analysis involving temperature, the heat transfer analysis was performed first, then the resulting temperatures at individual nodes were transferred to the respective structural analysis steps to perform the pure thermal stress analysis (case b) or the sequentially coupled thermal-mechanical stress analysis (case c).

\subsection{Material properties for heat transfer and structural analysis model}

The heat transfer and stress analysis FE models were developed by using temperature-dependent thermal and mechanical material properties data given in Ref. [23], which were originally considered from the ASME Boiler and Pressure Vessel Code [35]. In this preliminary model, because elastic structural analysis is considered, it is sufficient to consider only the elastic modulus and Poisson ratio. The present FE model uses length in $\mathrm{mm}$, stress in $\mathrm{MPa}$, and temperature in ${ }^{\circ} \mathrm{C}$. The original data taken from Ref. [23] employed British units, which were scaled appropriately to use in the present FE models. The material properties data given in [23] are for SA-508 carbon steel (or 508 low alloy steel) and SA-376 stainless steel (equivalent of 316 stainless steel). Figures 4 to 7 show the temperature-dependent elastic modulus, mean coefficient of thermal expansion, thermal conductivity, and specific heat capacity in SI units, respectively. The densities were assumed to be temperature independent and were considered to be 8027 and $7750 \mathrm{~kg} / \mathrm{m}^{3}$ for SA-376 and SA-508, respectively. Similarly, the Poisson ratios were assumed temperature independent and were considered to be 0.31 and 0.3 for SA-376 and SA508 , respectively. 


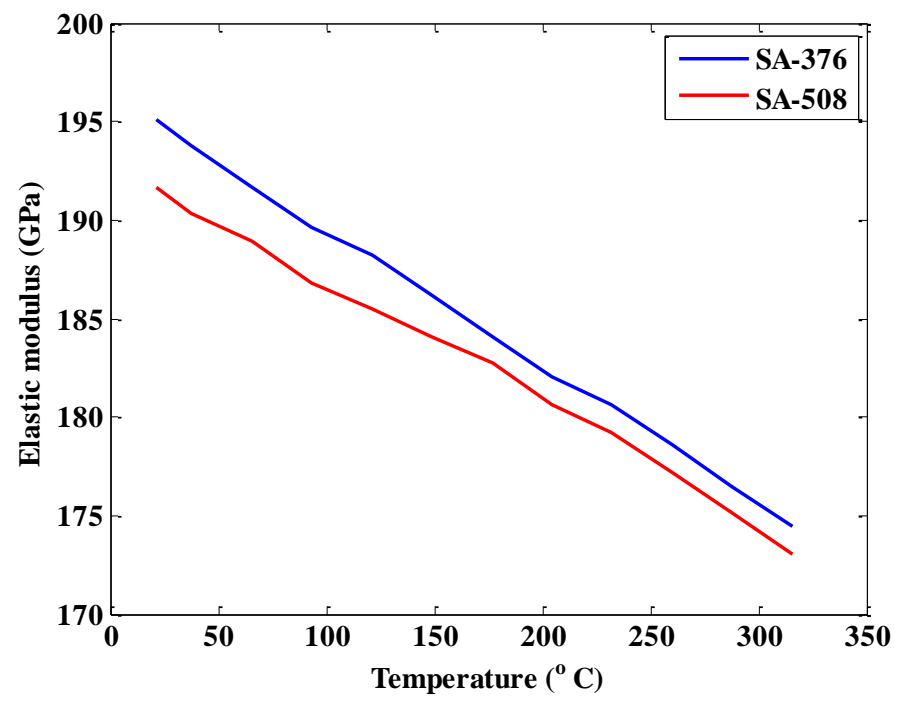

Figure 4 Temperature-dependent elastic modulus for SA-376 and SA-508

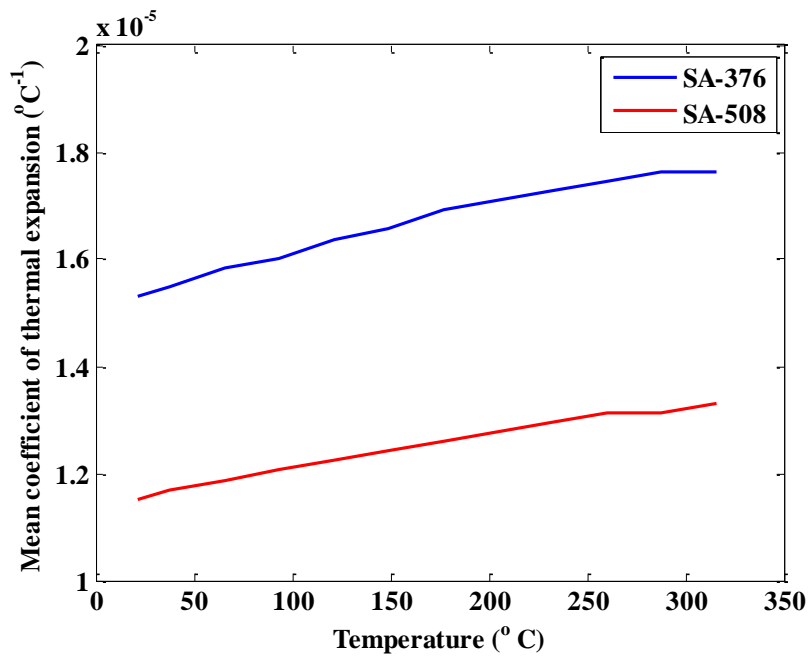

Figure 5 Temperature-dependent mean coefficient of thermal expansion for SA-376 and SA-508

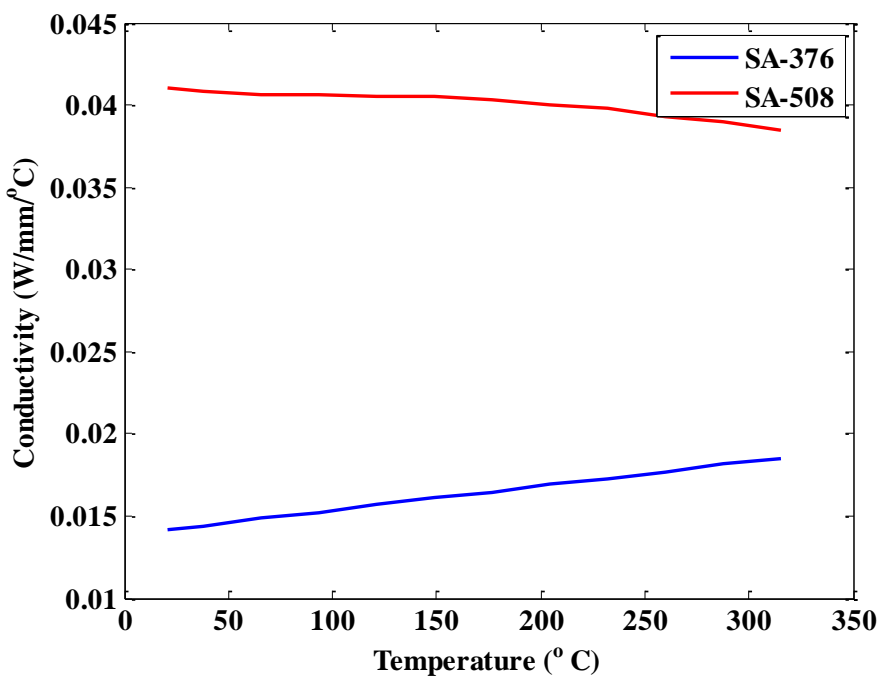


Figure 6 Temperature-dependent thermal conductivity for SA-376 and SA-508

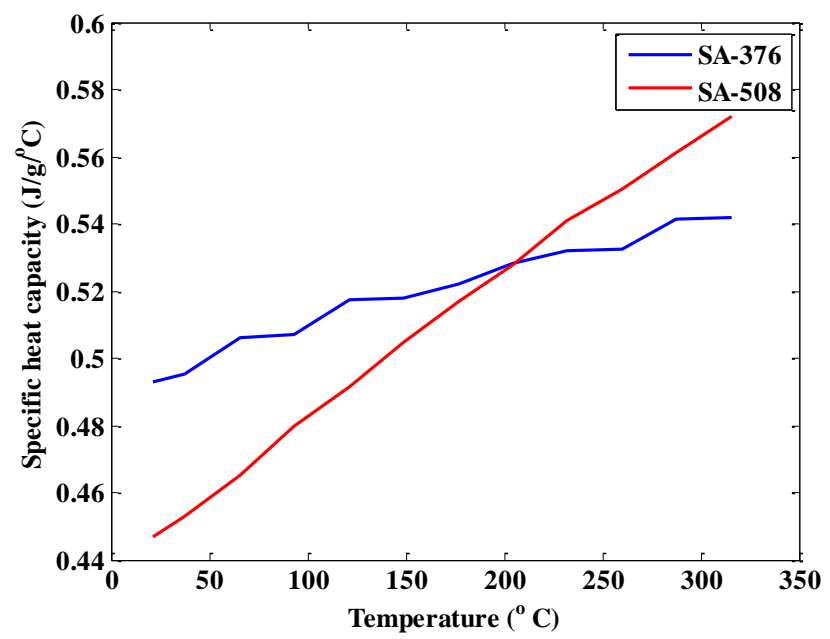

Figure 7 Temperature-dependent specific heat capacity for SA-376 and SA-508

\section{Results of Heat Transfer Analysis}

As discussed above, we have developed an assembly-level heat transfer model to estimate the temperature profile at a given location and at a given time. Some of the important results from this model are discussed below.

\subsection{Selection of artificial convective heat transfer coefficient}

Selection of appropriate heat transfer coefficient (4) is important for convective heat transfer analysis. Accurate heat transfer coefficients have to be estimated either based on rigorous thermo-hydraulic experiments or through computational fluid dynamics models. However, such analysis was beyond our scope. Rather, a simple relation between heat transfer coefficient $h$ and Nusselt number $N_{u}$ was used to estimate a first approximation of the heat transfer coefficient. This relation is given as

$$
N_{u}=\frac{h D_{e}}{k_{w}}
$$

The Nusselt number $N_{u}$ is estimated from the Dittus-Boelter correlation for turbulent heat transfer:

$$
N_{u}=0.023 R e^{0.8} \operatorname{Pr}^{n}
$$

In Eqs. 5 and 6, $D_{e}$ is the hydraulic diameter (assumed equal to the diameter of the hot leg, i.e. $0.66548 \mathrm{~m}$ in the present FE model $), k_{w}$ is the thermal conductivity of water $(0.6096 \mathrm{~W} / \mathrm{m}-\mathrm{K}$ at $300{ }^{\circ} \mathrm{C}$, [37]), $R e$ is the Reynolds's number (500,000 based on Ref. [7]), and $\operatorname{Pr}$ is the Prandtl number $\left(0.8601\right.$ at $300{ }^{\circ} \mathrm{C}$ and $15 \mathrm{MPa}$ [37]). Also, the coefficient $n$ in Eq. 6 is set equal to 0.3 assuming the fluid is being cooled. With these values, the first approximation of the heat transfer coefficient $h$ was calculated to be $715.5 \mathrm{~W} / \mathrm{m}^{2}-\mathrm{K}$. With this coefficient, an initial heat transfer analysis was performed for the above temperature boundary conditions. From the simulation 
results, we found that the temperature at the ID surface was not reaching the desired boundary value at the highest test temperature. This was possibly due to lower heat-up time and subsequent lower steady-state heating time. In an actual reactor, the individual duration for heat-up, cooldown, and steady-state normal operation will be much higher compared to the time durations considered for the example temperature cycles. However, increasing the duration for individual transient heat transfer steps would increase the overall times for heat transfer analysis computation. This increase would increase the subsequent times for structural analysis computation. To avoid large transient heat transfer time steps, the convective heat transfer coefficient was artificially increased. For example, for $315.56{ }^{\circ} \mathrm{C}$, the above estimated $h$ was increased by 10 times, to $7155 \mathrm{~W} / \mathrm{m}^{2}-\mathrm{K}$. For other temperatures, this film coefficient was linearly scaled. Two heat transfer analysis were performed using $h=715.5 \mathrm{~W} / \mathrm{m}^{2}-\mathrm{K}$ and $7155 \mathrm{~W} / \mathrm{m}^{2}-\mathrm{K}$. Figure 8 shows the resulting simulated temperatures at typical OD and ID nodes in the midsection of the RPV. This figure indicates that the estimated highest ID temperature with $h=$ $715.5 \mathrm{~W} / \mathrm{m}^{2}-\mathrm{K}$ is much lower compared to the desired highest ID temperature of $315.56{ }^{\circ} \mathrm{C}$ (see Figure 8). In contrast, the $h=7155 \mathrm{~W} / \mathrm{m}^{2}-\mathrm{K}$ case simulates fairly well the desired boundary condition temperature with the stipulated step time. Hence, we used $h=7155 \mathrm{~W} / \mathrm{m}^{2}-\mathrm{K}$ for the subsequent heat transfer analysis discussed later. Note that for most accurate fatigue evaluation of reactor component under both in-air and reactor coolant environmental conditions, it is necessary to consider actual plant and component specific transients. Considering actual plant specific transients in FE simulation would help simulating realistic rate of temperature raise/fall in component. In other hand this would help simulating realistic rate of stress-strain raise/fall in component, leading to more accurate estimation of stress/strain rate dependent fatigue lives (if only rate effect considered in fatigue evaluation). For example, to estimate fatigue lives of components under reactor environment, the approaches discussed in NUREG-6909 [21] requires accurate estimation of strain rate. However, for simplicity and due to the reasons discussed above, in the present FE model we had not considered heat-up and cool-down rates followed in an actual reactor. The FE model discussed in this paper is of very preliminary level. In future component level detailed FE models we will consider plant and component specific transients with more realistic temperature and pressure loading/unloading rates.

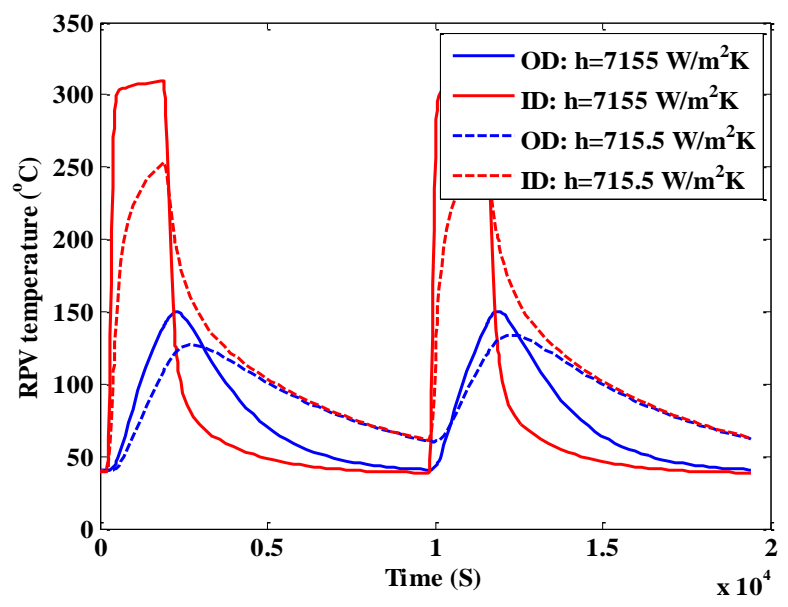

Figure 8 Simulated temperature at RPV mid-section OD and ID for different heat transfer coefficients 


\subsection{Linear versus quadratic heat transfer elements}

It is essential to select appropriate heat transfer elements for accurate estimation of the temperature distribution and, at same time, minimize the computational burden. For that purpose, we performed parametric studies considering both linear heat transfer elements (DC3D8) and quadratic heat transfer elements (DC3D20). Both assembly-level FE models were simulated in the batch mode using seven processors of a Linux cluster. From the simulation, we found that the FE model with DC3D8 elements took much less CPU time (approximately 15 minutes) compared to that of the FE model with DC3D20 elements (approximately 45 minutes). In addition, the linear element model generates a smaller output file that can easily be imported to the structural analysis model. At same time, the DC3D8-based heat transfer model gives fairly similar results to those for the DC3D20-based heat transfer model, as shown in Figure 9 for the simulated RPV mid-section OD and ID temperature. Hence, we used the DC3D8 elements for subsequent heat transfer models and for the corresponding stress analysis elements (C3D8) in the structural analysis.

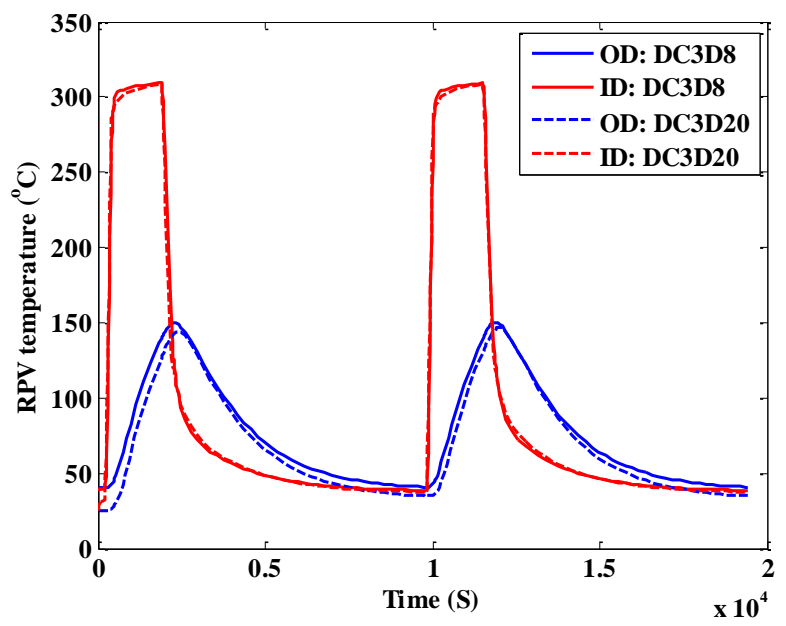

Figure 9 Simulated temperature at RPV mid-section OD and ID for DC3D8 and DC3D20 heat transfer elements

\subsection{Representative heat transfer analysis results}

Based on the cyclic temperature boundary conditions discussed earlier, the DC3D8 linear brick elements, and the heat transfer coefficient $h=7155 \mathrm{~W} / \mathrm{m}^{2}-\mathrm{K}$, we performed a heat transfer analysis for the full assembly-level model shown in Figure 2. Representative results are presented below. Figure 10 shows the OD and ID surface temperature distribution, at the end of 1900 seconds, i.e., at the end of step 3 in Table 2. Similarly Figure 11 shows the OD and ID surface temperature distribution, of the full assembly at the end of 19,420 seconds, i.e., at the end of step 9. In addition, time histories of temperatures were estimated at representative locations of different components. For example, Figures 12 and 13 show the time histories for simulated temperatures at typical OD and ID nodes in the elbow section of the HL and CL, respectively. 


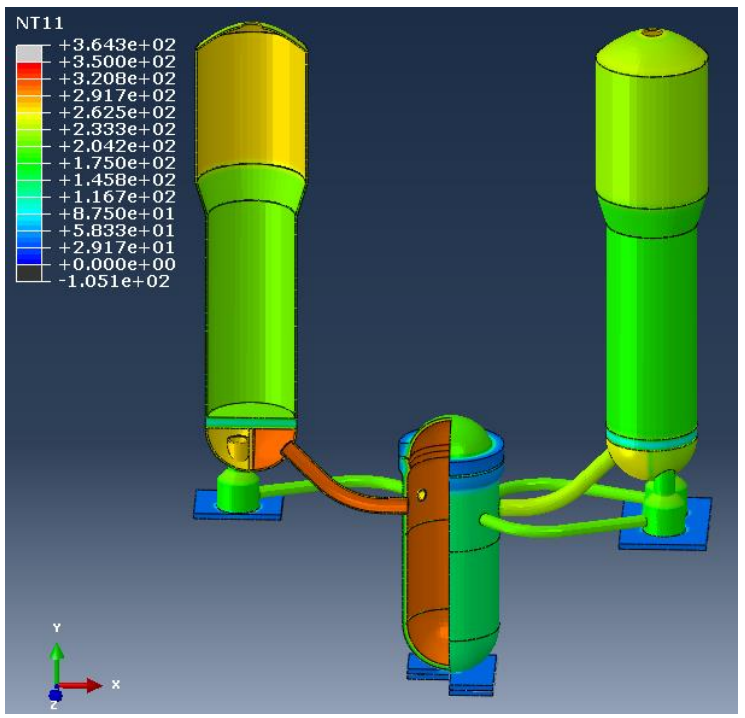

Figure 10 Distribution of OD and ID surface temperature (in ${ }^{\circ} \mathrm{C}$ ) of full assembly at the end of $1900 \mathrm{sec}$

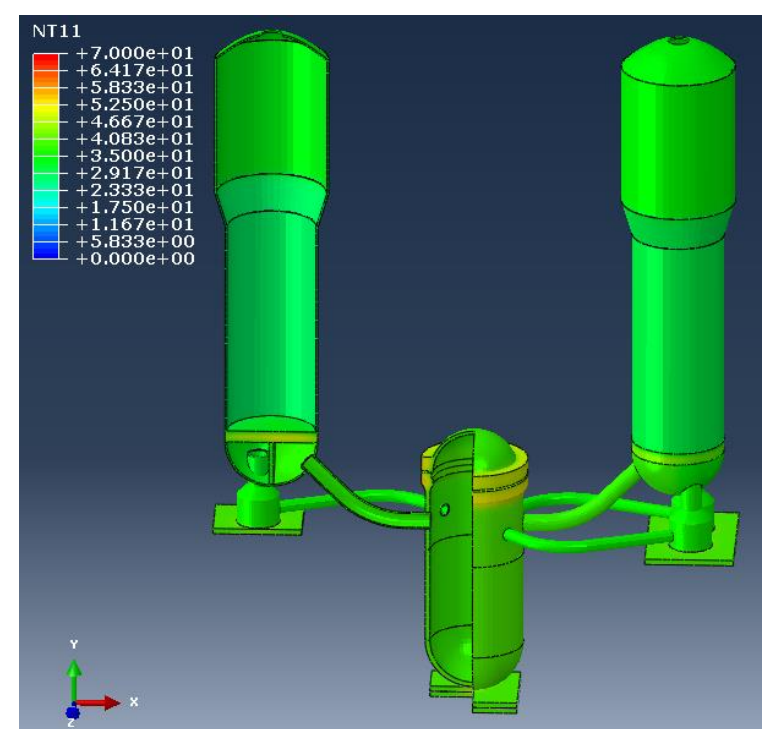

Figure 11 Distribution of OD and ID surface temperature (in ${ }^{\circ} \mathrm{C}$ ) of full assembly at the end of $19,420 \mathrm{sec}$ 


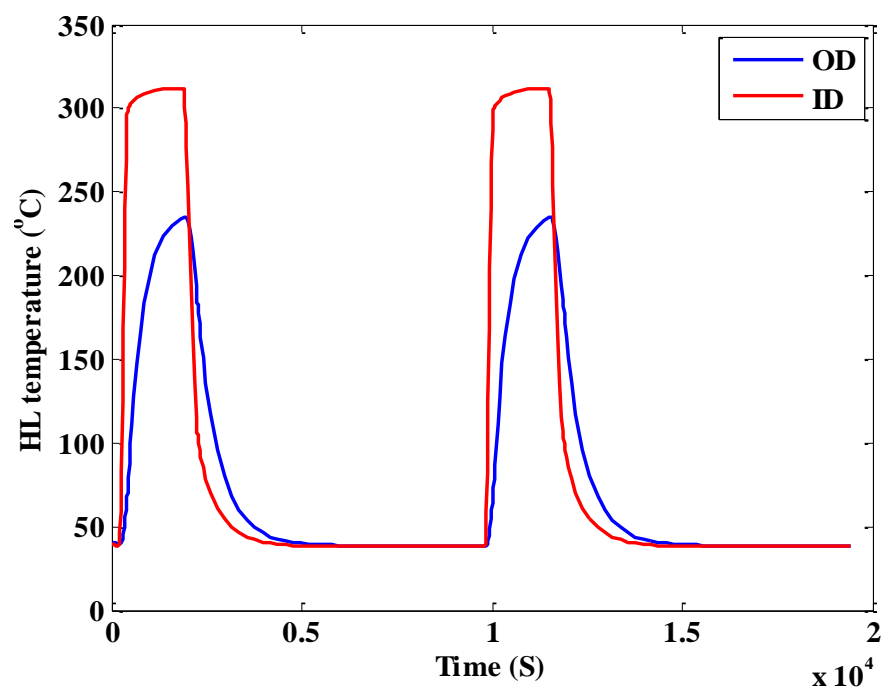

Figure 12 Time histories of simulated temperature at typical OD and ID nodes in elbow section of HL

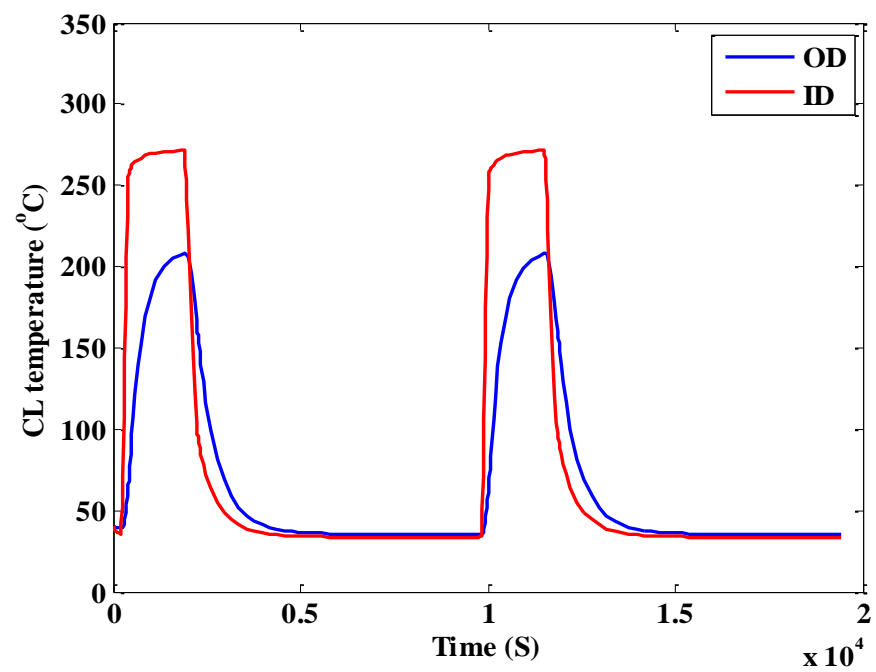

Figure 13 Time histories of simulated temperature at typical OD and ID nodes in elbow section of CL

\section{Results of Thermal-Mechanical Stress Analysis}

We performed stress analyses using the system-level FE model for three cases: pressure loading (case a), temperature loading (case b) or both at the same time (case c). For temperature loading, the nodal and time-dependent temperature distribution estimated through the heat transfer model was used in the structural analysis model to perform either pure thermal stress analysis (thermal load only) or sequentially coupled thermal-mechanical stress analysis. Separate stress analyses for temperature or pressure loading were performed to better understand the effect of individual loading components on overall stress analysis results performed under the combined thermal-mechanical load. The resulting stress analysis results were further considered for fatigue evaluation of some example components. The fatigue evaluation results will be discussed in the next section. Representative comparative stress analysis results are given below. Figure 14 shows the maximum principal stress distributions at the end of 1900 seconds (i.e., end 
of step 3 in Table 2), estimated for (a) pressure loading, (b) thermal loading, and (c) pressure and thermal loading. These figures show that the junction/nozzle area has maximum principal stress compared to other regions. For simplicity, in the discussed assembly level FE model we did not consider the detailed nozzle geometry as in a typical real reactor. In addition, due to unavailability of detail material properties for nozzle materials (e.g., dissimilar and similar metal welds); we did not specifically model the nozzle with weld material properties. Because of this, the actual absolute value of the stress at these hotspots may be quite different compared to our estimated values. Currently as part of LWRS program at ANL, we are conducting tensile and fatigue testing of both dissimilar and similar metal welds pertinent to RPV/SG nozzles. We will include the related material properties in a future detailed FE model study. Also note that later in the present paper, we discuss the fatigue life of some example components (e.g., HL and CL). Given that the present estimated nozzle stresses are not realistic, we thus did not consider the stress in the nozzle areas of the HL/CL in this fatigue evaluation. Instead, the stress and strain in the elbow region of the HL/CL were considered for the fatigue evaluation. Figure 15 shows the time histories for the maximum/minimum principal stress $\left(\sigma_{1} / \sigma_{3}\right)$ at a typical ID element in the HL elbow for (a) pressure loading, (b) thermal loading, and (c) pressure and thermal loading. Similarly, Figure 16 shows the time histories of the maximum/minimum principal stress at a typical ID element in the CL elbow for the three loadings. For the HL case, the maximum principal stress $\left(\sigma_{1}\right)$ for the combined pressure and thermal loading is much higher than those for the pressure or thermal only loadings. However, in the CL case, the maximum principal stress $\left(\sigma_{1}\right)$ for the combined thermal and pressure loading is similar or slightly lower than that for thermal loading only. These different trends for the HL and CL cases could be due to multi-axial stress interaction. In addition, the maximum principal strains were estimated from different stress analysis models for comparative study and fatigue evaluation. For example, Figure 17 shows the maximum principal strain $\left(\epsilon_{1}\right)$ distributions at the end of 1900 seconds estimated for the three loadings. This figure indicates that the CL experiences higher strain compared to the HL. This effect is more evident for the pure thermal loading and combined pressure and thermal loading. The reason for higher stress in the CL could be due to the thinner section of the CL (thickness $=55.88 \mathrm{~mm}$ ) compared to the HL (thickness $=60.96 \mathrm{~mm}$ ). Due to the thinner section of CL, there is a steeper temperature gradient across the CL cross section compared to that across the HL cross section. This difference leads to both higher strain and stress in the CL compared to the HL. The higher principal stress in the CL compared to the HL is evident from Figures 15 and 16. Furthermore, the higher principal strain in the CL compared to the HL can also be seen by comparing Figures 18 and 19. Note that Figures 18 and 19 show the maximum/minimum strain $\left(\epsilon_{1} / \epsilon_{3}\right)$ histories for stress analysis models with different loadings. From these figures, it also can be seen that, the maximum principal strain $\left(\epsilon_{1}\right)$ histories in the HL are largely compressive (particularly if thermal loading is applied), whereas in the case of the CL the maximum principal strain $\left(\epsilon_{1}\right)$ histories are tensile for all loading cases. In addition to the stress/strain comparisons, nodal displacements are presented. For example, Figure 20 shows the distributions of nodal displacement (magnitude) at the end of $1900 \mathrm{sec}$ for the three loadings. From this figure it can be seen that the SG nozzle ends of the HL and CL experience higher displacement for the thermal and pressure loading compared to the pressure or thermal loadings. Figures 21 and 22 show the time histories of nodal displacement magnitude $\left(U_{m a g}\right)$ at typical ID nodes in the end sections (near SG nozzle) of the HL and CL, respectively. 

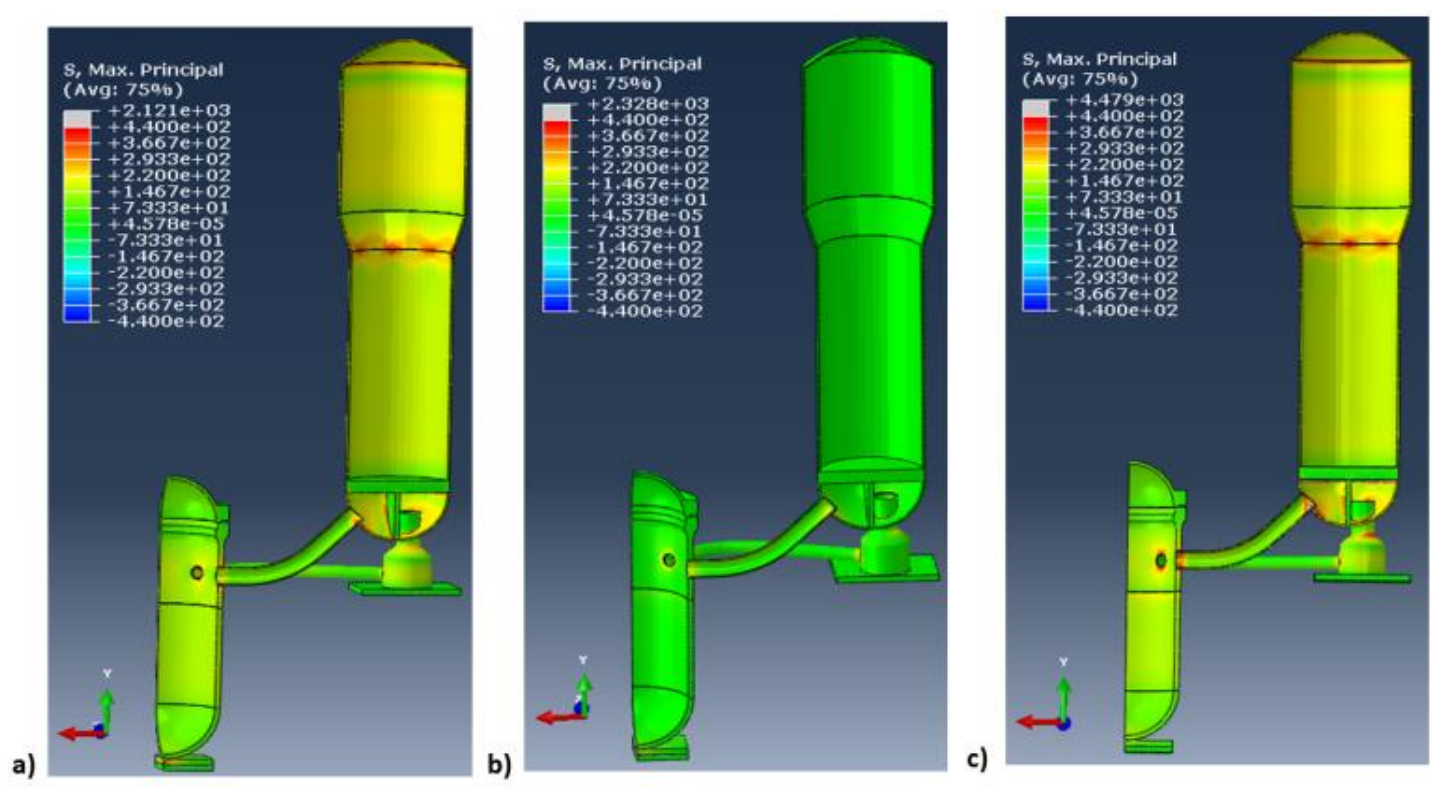

Figure 14 Maximum principal stress distribution (in MPa) at the end of $1900 \mathrm{sec}$ from stress analysis models with (a) pressure loading, (b) thermal loading, and (c) both pressure and thermal loading

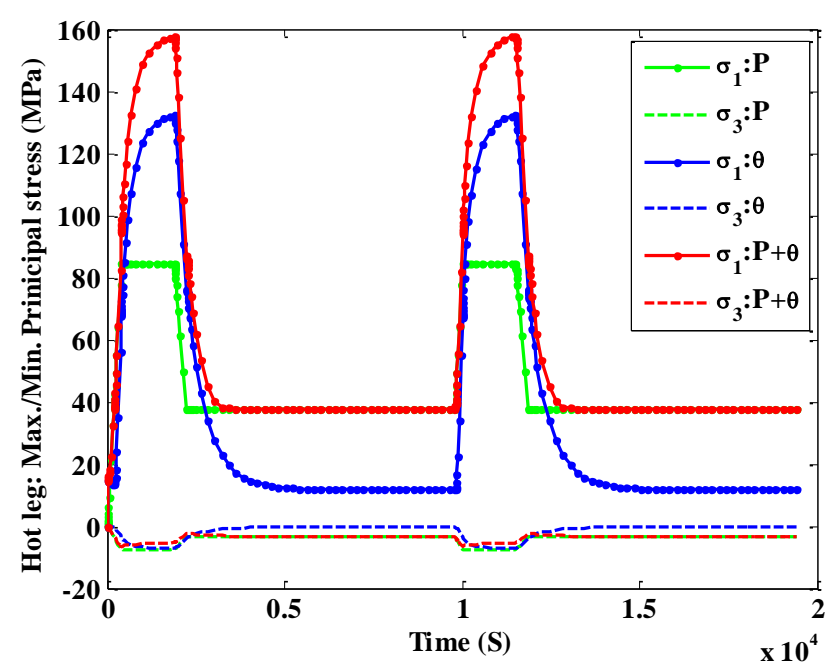

Figure 15 Maximum/minimum principal stress $\left(\sigma_{1} / \sigma_{3}\right)$ time histories at a typical ID element in the HL elbow from stress analysis models with pressure (P) loading, thermal $(\theta)$ loading, and both pressure and thermal $(\mathrm{P}+\theta)$ loading 


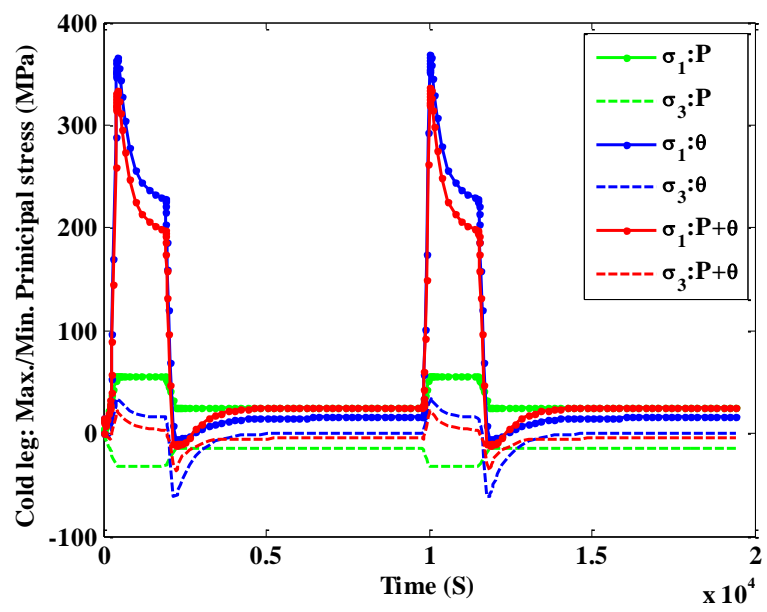

Figure 16 Maximum/minimum principal stress time histories at a typical ID element in CL elbow from stress analysis models with pressure $(\mathrm{P})$ loading, thermal $(\theta)$ loading, and both pressure and thermal $(\mathrm{P}+\theta)$ loading
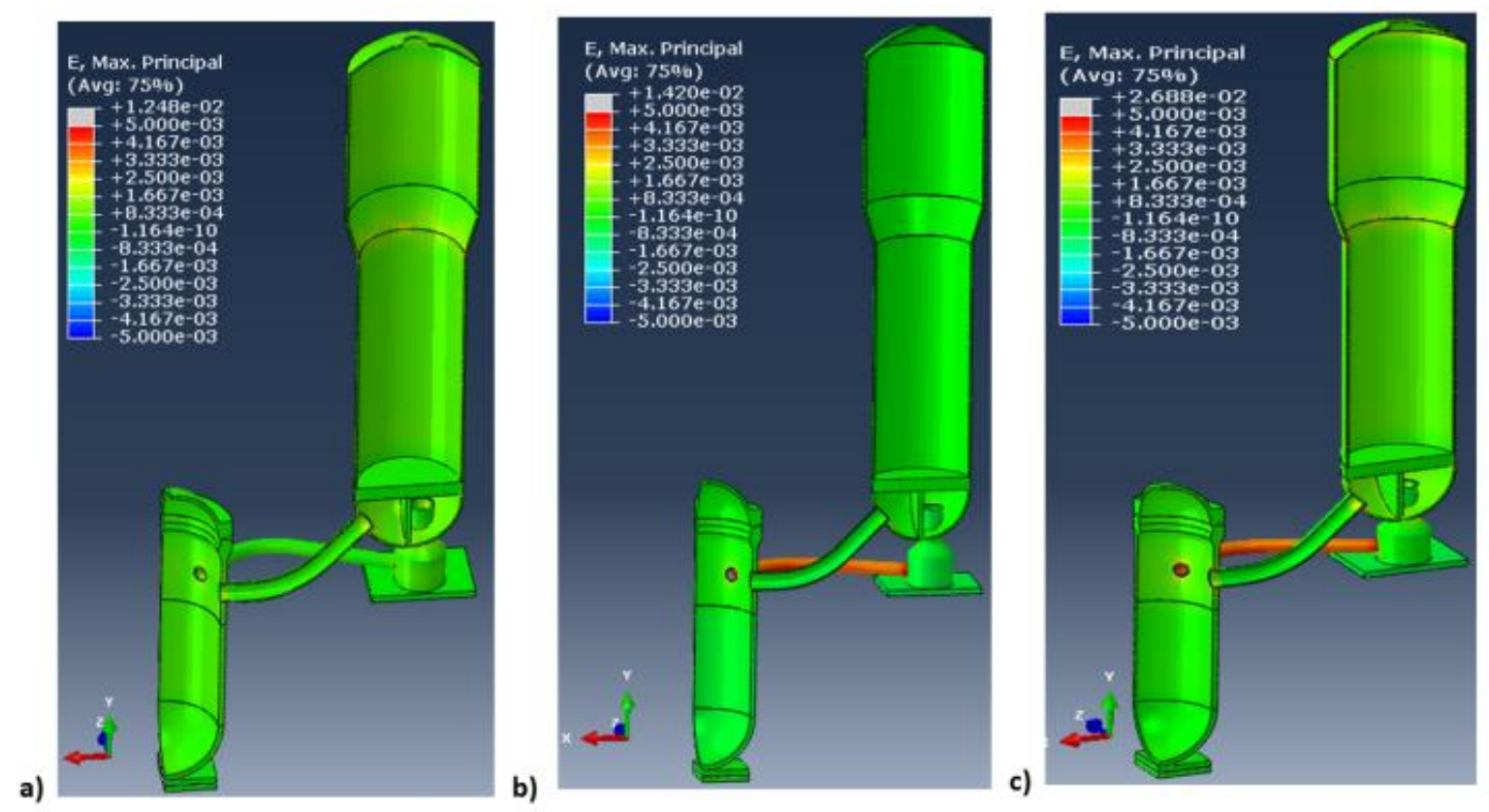

Figure 17 Maximum principal strain (in absolute scale) distribution at the end of $1900 \mathrm{sec}$ from stress analysis models with (a) pressure, (b) thermal, and (c) both pressure and thermal loading 


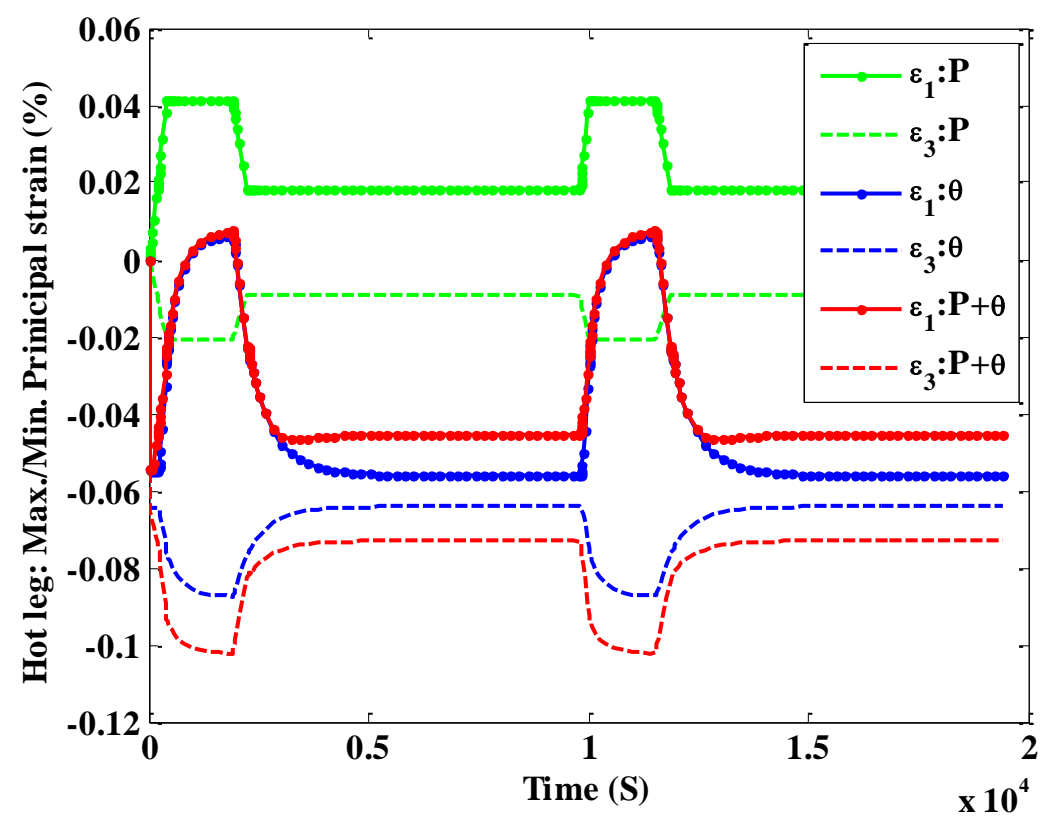

Figure 18 Maximum/minimum principal strain (\%) time histories at a typical ID element in HL elbow from stress analysis models with pressure $(\mathrm{P})$, thermal $(\theta)$, and both pressure and thermal $(\mathrm{P}+\theta)$ loading

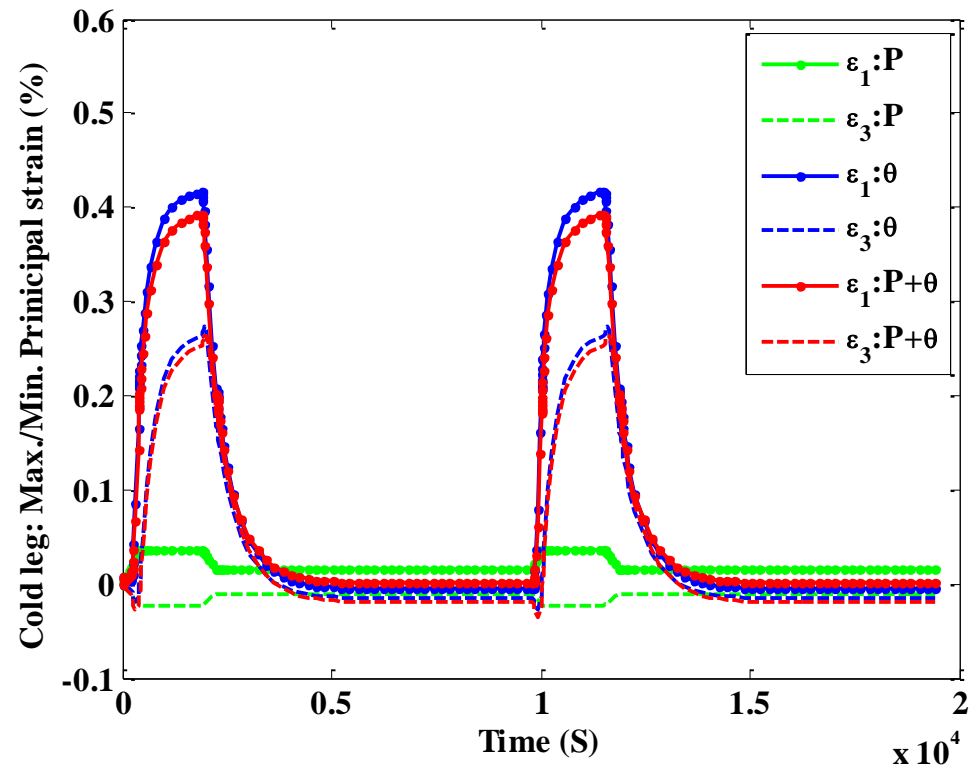

Figure 19 Maximum/minimum principal strain (\%) time histories at a typical ID element in CL elbow from stress analysis models with pressure $(\mathrm{P})$, thermal $(\theta)$, and both pressure and thermal $(\mathrm{P}+\theta)$ loading 

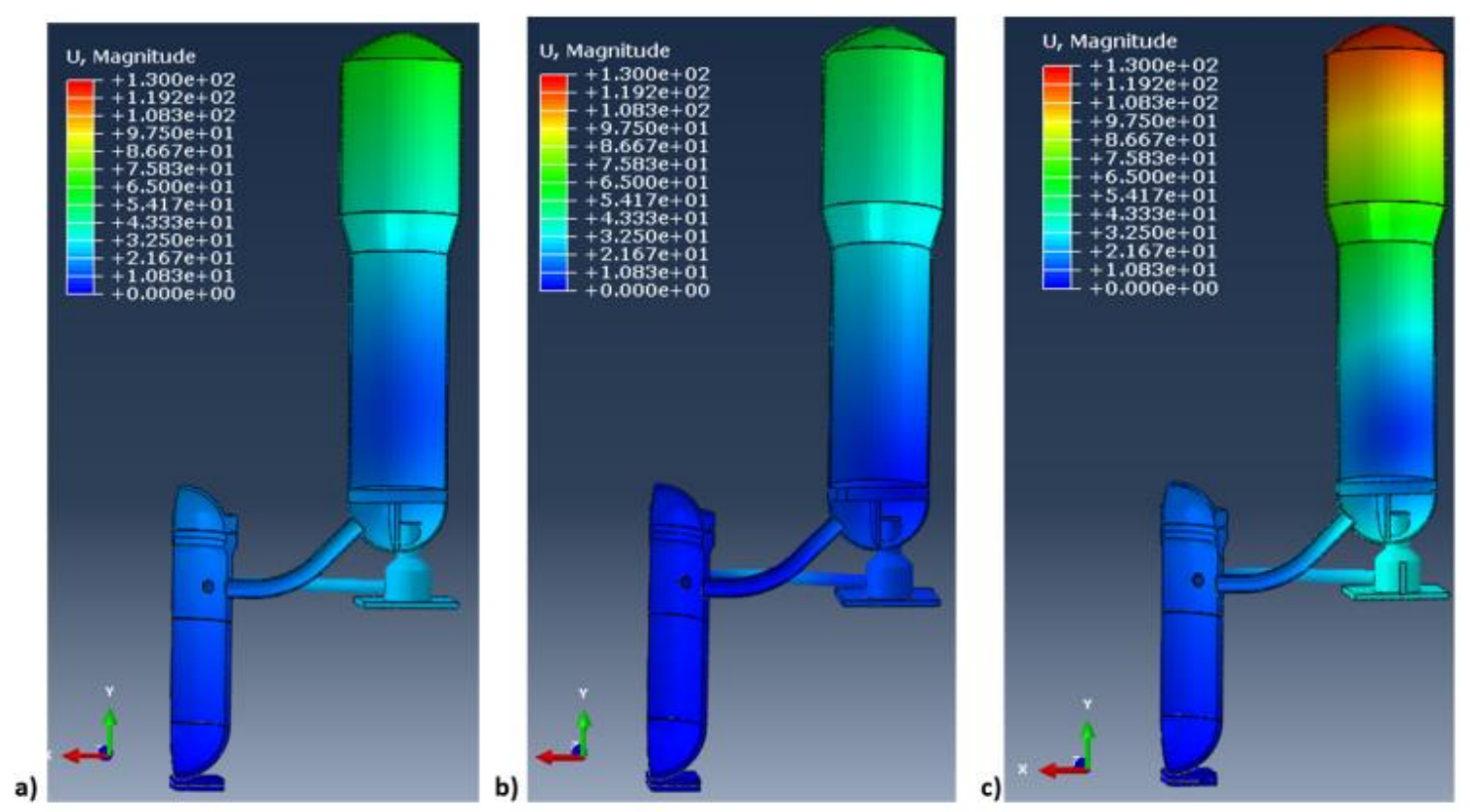

Figure 20 Displacement (magnitude in $\mathrm{mm}$ ) variation at the end of $1900 \mathrm{sec}$ from stress analysis models with (a) pressure loading, (b) thermal loading, and (c) both pressure and thermal loading

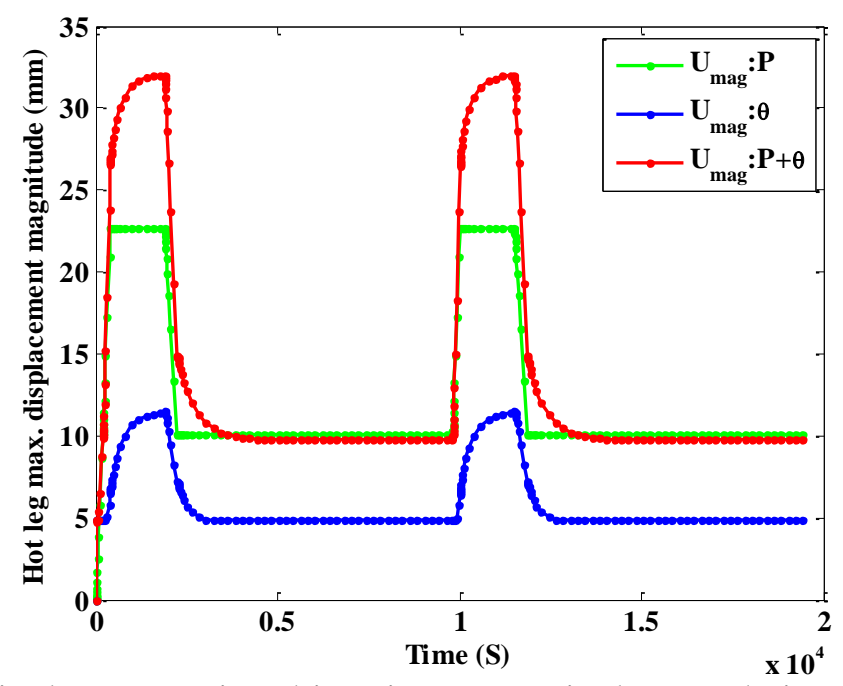

Figure 21 Maximum displacement time histories at a typical ID node in HL (near SG nozzle) from stress analysis models with pressure $(\mathrm{P})$ loading, thermal $(\theta)$ loading, and both pressure and thermal $(\mathrm{P}+\theta)$ loading 


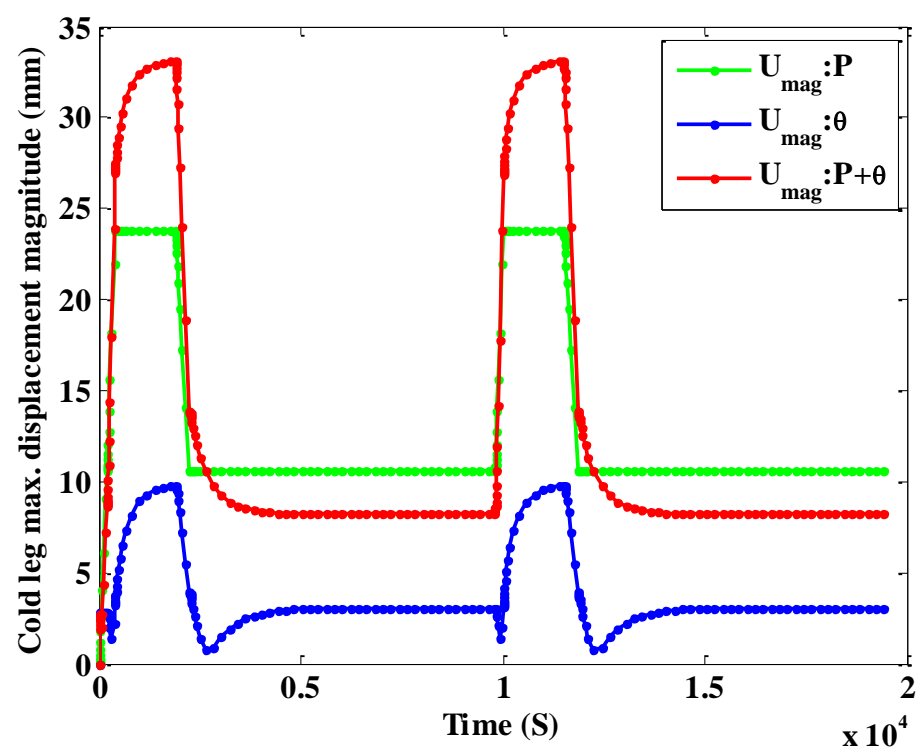

Figure 22 Maximum displacement time histories at a typical ID node in CL (near SG nozzle) from stress analysis models with pressure (P) loading, thermal $(\theta)$ loading, and both pressure and thermal $(\mathrm{P}+\theta)$ loading

\section{Environmental Fatigue Life Estimation for Example Components}

We performed preliminary fatigue analyses based on criteria from the ASME estimation of the in-air fatigue life [38] and from the NUREG-6909 [21] estimation of the environmental fatigue life. For the analyses, we chose two example components, such as the hot and cold legs. For the ASME-based fatigue evaluation, we used the maximum and minimum principal stress $\left(\sigma_{1}\right.$ and $\left.\sigma_{3}\right)$ histories given in Figures 15 and 16 to estimate the equivalent cyclic stress amplitude $\sigma_{a}$ at a given time ( $t$ ) using the following expression:

$$
\sigma_{a}(t)=\frac{1}{2}\left[\sigma_{1}(t)-\sigma_{3}(t)\right]
$$

ASME code design by analysis rules (NB-3200) uses Tresca criterion which states that the maximum shear stress at a point is equal to one-half the difference between the algebraically largest $\left(\sigma_{1}\right)$ and the algebraically smallest $\left(\sigma_{3}\right)$ of the three principal stresses at the point. Hence the estimation of stress amplitude $\sigma_{a}(t)$ using Eq. 7 would results in estimating the shear stress at a given time $(t)$. Figures 23 and 24 respectively show the stress amplitude time histories in HL and CL estimated using Eq. 7. Based on these time histories we estimated the maximum stress amplitude. For $\mathrm{i}^{\text {th }}$ fatigue cycle the expression for the maximum stress amplitude $\sigma_{a, i}^{\max }$ is given as:

$$
\sigma_{a, i}^{\max }=\max \left[\sigma_{a, i}(t)\right]-\min \left[\sigma_{a, i}(t)\right]
$$

Since, in the present example, both the thermal and pressure loadings yield the same stress/strain amplitude, only one fatigue cycle (say, cycle 2) was considered for the fatigue evaluation. Note in the present FE model we considered elastic material properties, hence it is expected that the stress or strain would not evolve over fatigue cycles. Hence it is justified to consider one fatigue cycle stress/strain results for fatigue evaluation. However, if cycle dependent elastic-plastic material parameters [39-41] are used the FE model may estimate different stress/strain results for different fatigue cycles, depending on the component geometry, boundary conditions, and 
loading severity. In that case it is essential to consider stress-strain from individual cycles separately. The estimated relative stress amplitudes for HL and CL are respectively given in Tables 3 and 4. Once the stress amplitude was estimated, we estimated the corresponding fatigue lives based on the in-air fatigue life curve for austenitic stainless steel given in the ASME code. For reference, the ASME in-air fatigue curve in SI units is given in Figure 25. While estimating the fatigue lives based on ASME fatigue curve, we made a necessary correction for the elevated temperature elastic modulus. The estimated in-air fatigue lives of the HL and CL under the three loading conditions are given in Tables 3 and 4, respectively.

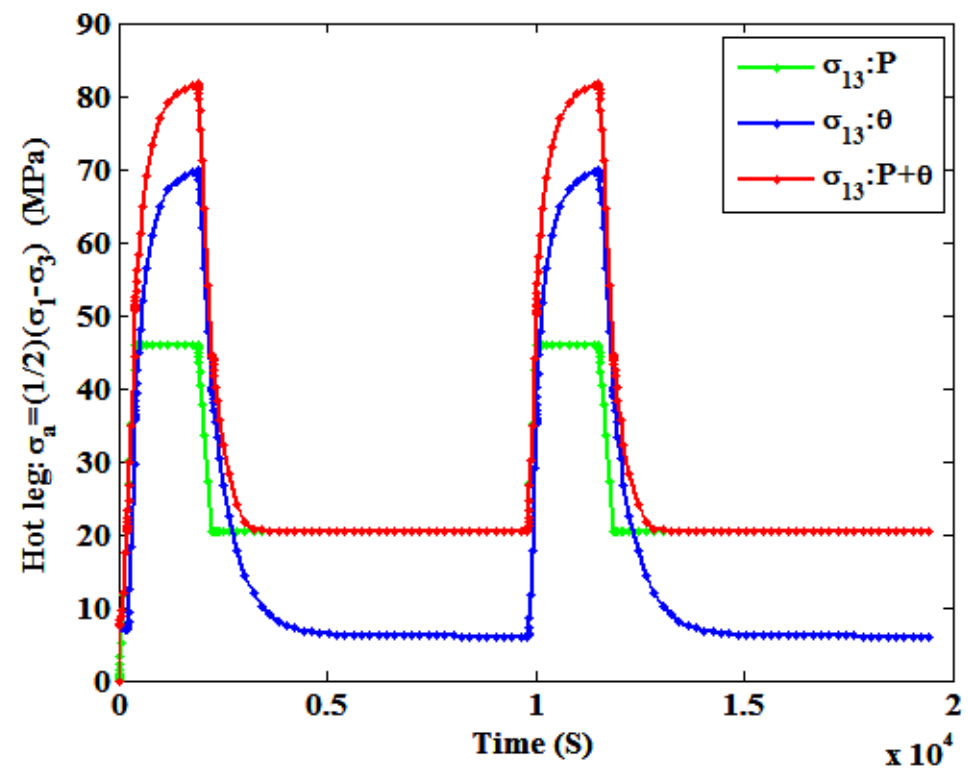

Figure 23 Stress amplitude time histories at a typical ID element in the HL elbow from stress analysis models with pressure $(\mathrm{P})$ loading, thermal $(\theta)$ loading, and both pressure and thermal $(\mathrm{P}+\theta)$ loading

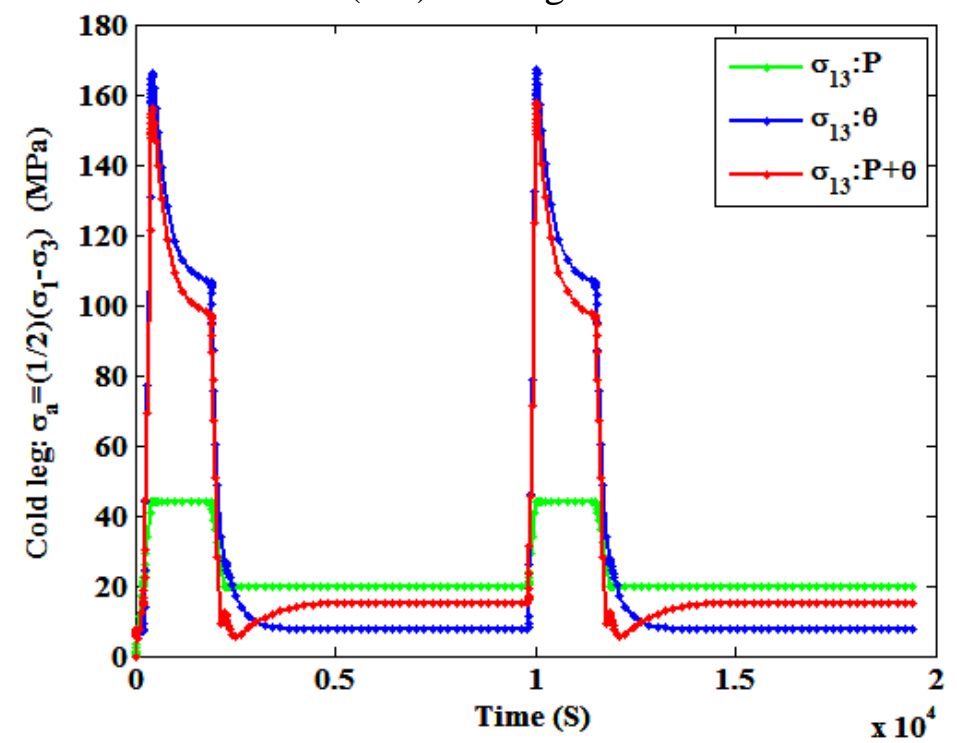

Figure 24 Stress amplitude time histories at a typical ID element in CL elbow from stress analysis models with pressure $(\mathrm{P})$ loading, thermal $(\theta)$ loading, and both pressure and thermal $(\mathrm{P}+\theta)$ loading 


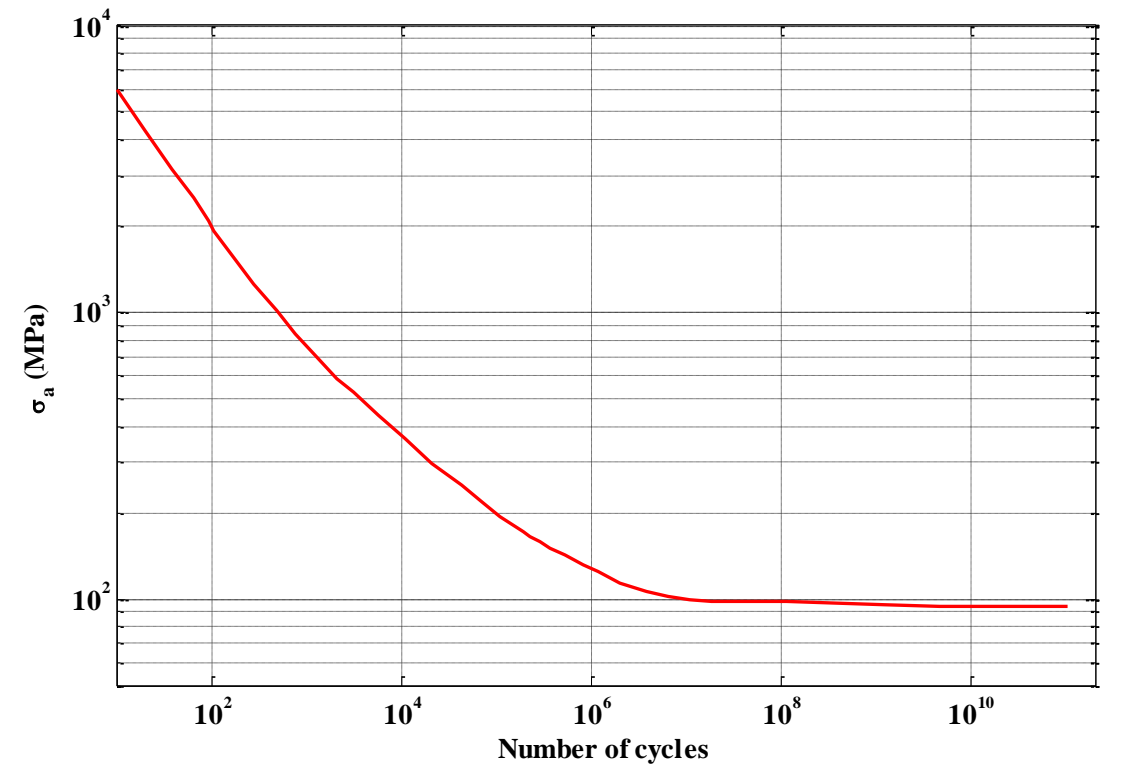

Figure 25 In-air fatigue design curve for austenitic stainless steel (ASME code [38])

Based on the estimated in-air condition fatigue lives $\left(N_{\text {air }}\right)$, we then determined the lives under the PWR environment $\left(N_{P W R}\right)$ applying the necessary environmental correction factor. The bases for estimating environmental correction factor for different reactor materials are elaborated in NUREG/CR-6909 [21]. Since, in the present FE model we used stainless steel material for HL and CL we need to use environmental correction factor for stainless steel to estimate the corresponding fatigue lives under PWR environment. Also note the HL and CL in majority of world's operating PWRs are made from stainless steel [28]. Based on the procedure discussed in NUREG/CR-6909 we estimated the PWR environment lives for HL and CL and the procedure is briefly discussed below. For example, the PWR environment life $\left(N_{P W R}\right)$ can be estimated from corresponding in-air life $\left(N_{\text {air }}\right)$ using:

$$
N_{P W R}=\frac{N_{a i r}}{F_{e n}}
$$

where $F_{e n}$ is the environmental correction factor. For cast austenitic stainless steel, this factor is given as

$$
F_{\text {en }}=\exp \left(-\theta^{\prime} O^{\prime} \dot{\epsilon}^{\prime}\right)
$$

In Eq. 9, $\theta^{\prime}, O^{\prime}$, and $\dot{\epsilon}^{\prime}$ are transformed temperature, strain rate, and DO, respectively. For a maximum hot leg temperature of $315.56{ }^{\circ} \mathrm{C}$ and a maximum cold leg temperature of $275^{\circ} \mathrm{C}$, the transformed temperature $\theta^{\prime}$ has the following form:

$$
\theta^{\prime}=\frac{(\theta-100)}{250}
$$

For strain rate $\dot{\epsilon}<0.0004 \% / s$, the transformed strain rate has the following form:

$$
\dot{\epsilon}^{\prime}=\ln \left(\frac{0.0004}{10}\right)
$$


In Eq. 10, for PWR water $O^{\prime}$ is equal to 0.29 . We determined the transformed strain rate $\dot{\epsilon}^{\prime}$ in Eqs. 10 and 12 based on the estimated maximum strain rate. The maximum strain rate was estimated from the cyclic strain amplitude. Similar as cyclic stress amplitude (Eq.7), the cyclic strain amplitudes were estimated using the $\mathrm{FE}$ estimated time histories of maximum and minimum principal strains $\left(\epsilon_{1}\right.$ and $\left.\epsilon_{3}\right)$. The expression for the cyclic strain amplitude in terms of maximum and minimum principal strains $\left(\epsilon_{1}\right.$ and $\left.\epsilon_{3}\right)$ is given below:

$$
\epsilon_{a}(t)=\frac{1}{2}\left[\epsilon_{1}(t)-\epsilon_{3}(t)\right]
$$

Note the NUREG/CR-6909 does not mandate to estimate strain amplitude using any particular method, but suggest estimating the strain amplitude from the estimated principal stress histories. Based on the NUREG/CR-6909 the strain amplitude at a given time can be found using:

$$
\epsilon_{a}(t)=\frac{1}{2 E}\left[\sigma_{1}(t)-\sigma_{3}(t)\right]
$$

In Eq. $14 E$ represent the elastic modulus, which is ideally temperature dependent. However (possibly for simplicity in using Eq. 14), NUREG/CR-6909 suggests using constant elastic modulus estimated at maximum temperature. Contrary to Eq. 14, in Eq. 13 there is no term associated with elastic modulus. While estimating the principal strains (in Eq. 13) FE methods automatically consider the time-dependent (in other word temperature dependent) behavior of elastic modulus. Hence, it is assumed that Eq. 13 would estimate more accurate results than Eq. 14. Using Eq. 13 and 14 time histories of strain amplitudes were estimated for HL and the comparative results are shown in Figure 26. Similarly time histories of strain amplitudes were estimated for CL and the results are shown in Figures 27. From the Figures 26 and 27 it can be seen that Eq. 14 under predicts the strain amplitude compared to Eq. 13. The under prediction of strain may results in conservative estimation of fatigue lives. Hence for more accuracy, we suggest to use Eq. 13 instead of Eq. 14 for estimation of environmental correction factors and the associated fatigue lives. The results discussed further in this paper are based on strain amplitude estimated through Eq. 13. Using Eq. 13 we estimated the $i^{\text {th }}$ fatigue cycle maximum strain amplitude. The expression for the maximum strain amplitude $\varepsilon_{a, i}^{\max }$ is given as:

$$
\varepsilon_{a, i}^{\max }=\max \left[\varepsilon_{a, i}(t)\right]-\min \left[\varepsilon_{a, i}(t)\right]
$$

Corresponding to a maximum strain amplitude $\varepsilon_{a, i}^{\max }$ the strain rate $(\dot{\epsilon})$, and the environmental correction factor $F_{e n}$ were estimated under different loading conditions. Based on the estimated environmental correction factor, the previously estimated in-air fatigue lives were corrected by using Eq. 9. Note that NUREG-6909 suggests a threshold value of $0.1 \%$ strain amplitude, below which environmental effects on the in-air fatigue lives do not occur. Accordingly, if the strain amplitude is less than $0.1 \%$ (in this example, for the hot leg), the environmental correction factor is assumed to be equal to one, meaning there is no correction due to the environment. Tables 3 and 4 show the estimated relative strain amplitude, strain rate, environmental correction factor, and associated fatigue lives under PWR conditions for the hot and cold legs, respectively. Note that while estimating the fatigue life of HL and CL we only considered the second cycle data and only from beginning of the second cycle (refer Table 2) to the time of maximum loading amplitude. However, in actual reactor the heat up and cool down procedures are conducted in multiple steps. Hence for more realistic fatigue life evaluation, FE simulation has to be conducted under real plant/component specific transients. Then the resulting FE based stress analysis results to be used for estimating the individual time step usages factor and finally the 
overall cumulative usages factor has to be estimated. The detailed stress analysis and fatigue evaluation under plant/component specific transients is one of our future works.

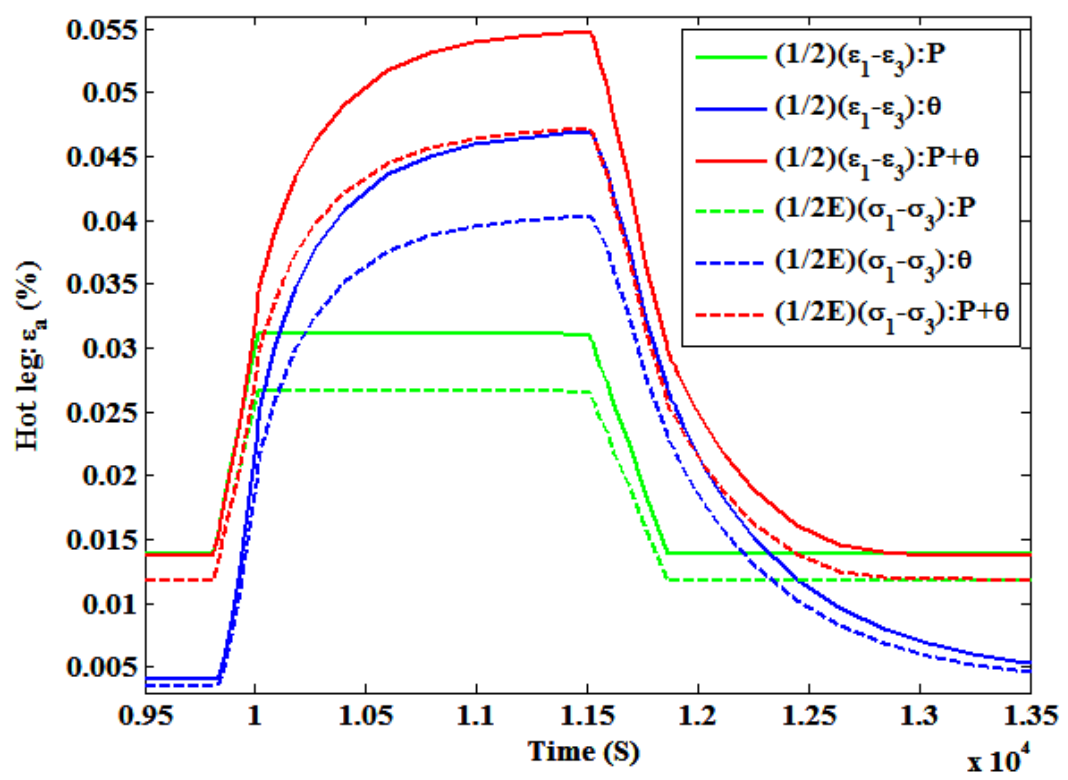

Figure 26 Strain amplitude time histories (using Eq. 13 and Eq. 14) at a typical ID element in the HL elbow from stress analysis models with pressure (P) loading, thermal ( $\theta$ ) loading, and both pressure and thermal $(\mathrm{P}+\theta)$ loading

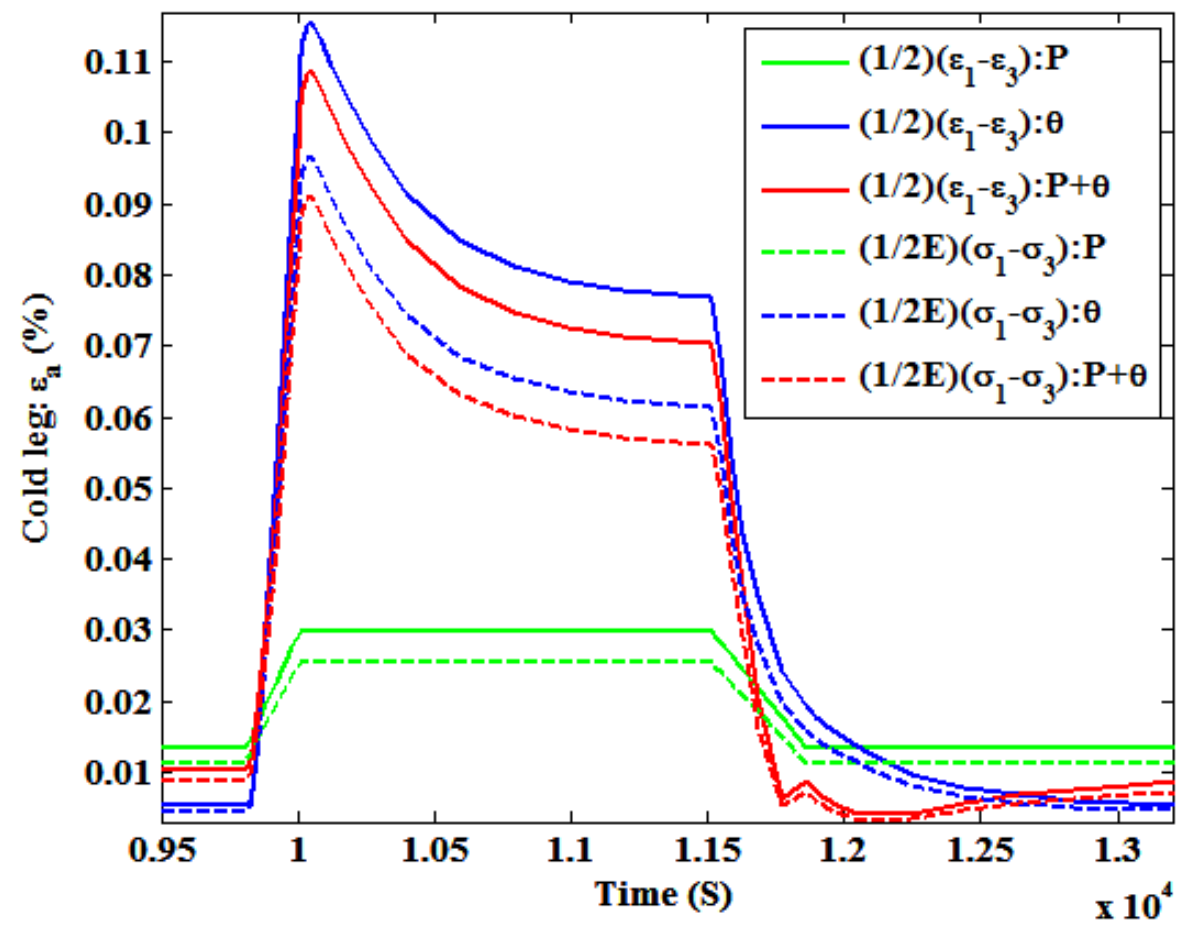

Figure 27 Strain amplitude time histories (using Eq. 13 and Eq. 14) at a typical ID element in the HL elbow from stress analysis models with pressure (P) loading, thermal ( $\theta$ ) loading, and both pressure and thermal $(\mathrm{P}+\theta)$ loading 
Table 3 In-air and environmental fatigue lives estimated under different loading conditions for hot leg

\begin{tabular}{|c|c|c|c|}
\hline $\begin{array}{c}\text { Hot leg } \\
\text { (based on elbow stress/strain) }\end{array}$ & $\begin{array}{c}\text { Only } \\
\text { pressure }\end{array}$ & $\begin{array}{c}\text { Only } \\
\text { temperature }\end{array}$ & $\begin{array}{c}\text { Both temperature } \\
\text { and pressure }\end{array}$ \\
\hline Max. stress amplitude (MPa) estimated using Eq. 8 & 25.559 & 63.81 & 61.211 \\
\hline Max. stress with elastic modulus correction & 28.811 & 71.928 & 68.998 \\
\hline Max. stain amplitude (\%) estimated using Eq. 15 & 0.017297 & 0.042841 & 0.041096 \\
\hline Max. strain rate (\%/s) & $1.0175 \times 10^{-5}$ & $2.5201 \times 10^{-5}$ & $2.4174 \times 10^{-5}$ \\
\hline In-air fatigue life & $>10^{6}$ & $>10^{6}$ & $>10^{6}$ \\
\hline$F_{e n}$ & 1 & 1 & 1 \\
\hline PWR environ. fatigue life & $>10^{6}$ & $>10^{6}$ & $>10^{6}$ \\
\hline
\end{tabular}

Table 4 In-air and environmental fatigue lives estimated under different loading conditions for

\begin{tabular}{|c|c|c|c|}
\hline $\begin{array}{c}\text { Cold leg } \\
\text { (based on elbow stress/strain) }\end{array}$ & $\begin{array}{c}\text { Only } \\
\text { pressure }\end{array}$ & $\begin{array}{c}\text { Only } \\
\text { temperature }\end{array}$ & $\begin{array}{c}\text { Both temperature } \\
\text { and pressure }\end{array}$ \\
\hline Max. stress amplitude (MPa) estimated using Eq. 8 & 24.561 & 159.53 & 142.4 \\
\hline Max. stress with elastic modulus correction & 27.685 & 179.83 & 160.52 \\
\hline Max. stain amplitude (\%) estimated using Eq. 15 & 0.016621 & 0.11025 & 0.098546 \\
\hline Max. strain rate (\%/s) & $9.7771 \times 10^{-6}$ & $6.4855 \times 10^{-5}$ & $5.7968 \times 10^{-5}$ \\
\hline In-air fatigue life & $>10^{6}$ & $1.5 \times 10^{5}$ & $2.8 \times 10^{5}$ \\
\hline$F_{\text {en }}$ & 1 & 7.8124 & 1 \\
\hline PWR environ. fatigue life & $>10^{6}$ & 19,200 & $2.8 \times 10^{5}$ \\
\hline
\end{tabular}

\section{Summary}

A system-level preliminary FE model was developed for a two-loop PWR reactor. This model was then used to conduct a system-level heat transfer analysis and subsequent thermalmechanical stress analysis for typical design-basis thermal-mechanical cycles. The stress analysis results were then used to estimate in-air fatigue lives of example components, such as the hot and cold legs, based on estimation criteria for the ASME in-air fatigue life and the fatigue design curve. Furthermore, estimated stress and strain histories were used to calculate environmental correction factors and associated PWR environment fatigue lives for the hot and cold legs based on the approach described in NUREG-6909. Followings are some key findings: 
a) The aim of the present work was to explore the possibility of developing a system level FE model for cyclic stress-strain analysis and fatigue evaluation. The developed system level FE model shows the possibility of cyclic stress analysis of a full scale reactor with multiple components.

b) This system level FE model helps to identify structural hotspots in the overall assembly of components.

c) Stress analysis results from this system level FE model will help as guide lines to compare stress analysis results from component level FE models. Particularly the effect of thermal expansion can more accurately be modeled through a system level FE model (with assembly level displacement/thermal boundary conditions) than a component level FE model (with isolated displacement/thermal boundary conditions).

d) The paper also presents a detailed procedure to perform cyclic stress analysis of reactor components and then using the resulting stress-strain data to estimate fatigue lives under in-air and PWR water environment.

The discussed models and results are very preliminary. Further development of the model is required for more accurate life prediction of reactor components. For example detailed component level model with finer FE mesh would improve the accuracy of stress analysis results. In addition, simulating under realistic plant and component specific transients (both temperature and pressure) would results in more accurate stress-strain results. More accurate stress-strain results would help to estimate more accurate fatigue lives of components. The above mentioned suggested improvement will be incorporated in our future FE and fatigue evaluation models.

\section{Acknowledgments}

This research was supported through the U.S. Department of Energy's Light Water Reactor Sustainability program under the work package of environmental fatigue study, program manager Dr Jeremy Busby.

\section{References}

1. Department of Energy, The Nuclear Energy Advanced Modeling and Simulation (NEAMs) Program (http://energy.gov/sites/prod/files/2013/07/f2/NEAMS\%20Executive\%20Program\%20Plan.pdf).

2. Palmtag, S., Clarno, K., Davidson, G., Salko, R., Evans, T., Turner, J., \& Schmidt, R. (2014). Coupled neutronics and thermal-hydraulic solution of a full core PWR using VERA-CS. Proceedings of International Topical Meeting on Advances in Reactor Physics (PHYSOR), Kyoto, Japan, September 28-October 3, 2014.

3. Kang, D. G., Jhung, M. J., \& Chang, S. H. (2011). Fluid-structure interaction analysis for pressurizer surge line subjected to thermal stratification. Nuclear Engineering and Design, 241(1), 257-269.

4. Conner, M. E., Hassan, Y. A., \& Dominguez-Ontiveros, E. E. (2013). Hydraulic benchmark data for PWR mixing vane grid. Nuclear Engineering and Design, 264, 97-102.

5. Yoon, H. Y., Cho, H. K., Lee, J. R., Park, I. K., \& Jeong, J. J. (2012). Multi-scale thermal-hydraulic analysis of PWRs using the CUPID code. Nuclear Engineering and Technology, (8), 831-846.

6. Murase, M., Minami, N., Nagae, T., \& Tomiyama, A. (2010). Countercurrent gas liquid flow in a PWR hot leg during reflux condensation. Dr. Valentin Uchanin (Ed.), InTech. Available from: http://www.intechopen.com/books/steam-generator-systems-operational-reliability-andefficiency/countercurrent-flow-in-a-pwr-hot-leg-under-reflux-condensation. 
7. Shan, J., Zhang, B., Gou, J., \& Cao, L. (2014). Subchannel Analysis, CFD Modeling and Verifications, CHF Experiments and Benchmarking. Science and Technology of Nuclear Installations, Volume 2014, Hindawi Publishing Corporation.

8. Lin, T., Li, R., Long, H., \& Ou, H. (2006). Three-dimensional transient sealing analysis of the bolted flange connections of reactor pressure vessel. Nuclear Engineering and Design, 236(24), 2599-2607.

9. Yu, S., Liu, J., Zuo, W., \& He, S. (2002). Sealing behavior of the HTR-10 pressure vessel flanges. Nuclear Engineering and Design, 216(1), 247-253.

10. Jia, X., Chen, H., Li, X., Wang, Y., \& Wang, L. (2014). A study on the sealing performance of metallic Crings in reactor pressure vessel. Nuclear Engineering and Design, 278, 64-70.

11. Mohanty, S., Majumdar, S., \& Srinivasan, M. (2013). Constitutive modeling and finite element procedure development for stress analysis of prismatic high temperature gas cooled reactor graphite core components. Nuclear Engineering and Design, 260, 145-154.

12. Mohanty, S., Jain, R., Majumdar, S., Tautges, T. J., \& Makuteswara, S. Coupled thermal-irradiation-structural analysis of HGTR fuel brick using ABAQUS. Proceedings of ICAPP '12, Chicago, June 24-28, 2012, Paper 12352.

13. Mohanty, S., Majumdar, S., \& Natesan, K., Modeling of steam generator tube rupture using extended finite element method. Structural Mechanics in Reactor Technology (SMiRT)-22 Conference, San Francisco, California, August 18-23, 2013.

14. Chen, M., Lu, F., Wang, R., \& Ren, A. (2014). Structural integrity assessment of the reactor pressure vessel under the pressurized thermal shock loading. Nuclear Engineering and Design, 272, 84-91.

15. Qian, G., \& Niffenegger, M. (2013). Procedures, methods and computer codes for the probabilistic assessment of reactor pressure vessels subjected to pressurized thermal shocks. Nuclear Engineering and Design, 258, 3550.

16. Qian, G., \& Niffenegger, M. (2013). Integrity analysis of a reactor pressure vessel subjected to pressurized thermal shocks by considering constraint effect. Engineering Fracture Mechanics, 112, 14-25.

17. Keim, E., Schmidt, C., Schöpper, A., \& Hertlein, R. (2001). Life management of reactor pressure vessels under pressurized thermal shock loading: Deterministic procedure and application to Western and Eastern type of reactors. International Journal of Pressure Vessels and Piping, 78(2), 85-98.

18. González-Albuixech, V. F., Qian, G., \& Niffenegger, M. (2014). Integrity analysis of reactor pressure vessels subjected to pressurized thermal shocks by XFEM. Nuclear Engineering and Design, 275, 336-343.

19. Qian, G., \& Niffenegger, M. (2015). Investigation on constraint effect of a reactor pressure vessel subjected to pressurized thermal shocks. Journal of Pressure Vessel Technology, 137(1), 011204.

20. Villanueva, W., Tran, C. T., \& Kudinov, P. (2012). Coupled thermo-mechanical creep analysis for boiling water reactor pressure vessel lower head. Nuclear Engineering and Design, 249, 146-153.

21. Chopra, O., and Stevens, G. (2014). Effect of LWR Coolant Environments on the Fatigue Life of Reactor Materials. U.S. Nuclear Regulatory Commission Report No. NUREG/CR-6909, Revision 1.

22. Japan Nuclear Energy Safety Organization (2011). Nuclear Power Generation Facilities Environmental Fatigue Evaluation Method for Nuclear Power Plants. Nuclear Energy System Safety Division, Japan Nuclear Energy Safety Organization Report No. JNES-SS-1005.

23. Gray, M. A., \& Verlinich, M. M. (2012). Guidelines for Addressing Environmental Effects in Fatigue Usage Calculations. Electric Power Research Institute Report EPRI--1025823.

24. Chen, B. Y., Huang, C. C., Chou, H. W., Lin, H. C., Liu, R. F., Weng, T. L., \& Chang, H. J. (2014). Reactor pressure vessel integrity assessment by probabilistic fracture mechanics-A plant specific analysis. International Journal of Pressure Vessels and Piping, 117, 64-69.

25. Mohanty, S., Soppet, W. K., Majumdar, S.. and Natesan, K. (2013). Report on Assessment of EnvironmentallyAssisted Fatigue for LWR Extended Service Conditions. Argonne National Laboratory Report ANL/LWRS13/3 (http://www.osti.gov/scitech/biblio/1168222).

26. Mohanty, S., Soppet, W. K., Majumdar, S. and Natesan, K. (2014). Environmental Effect on Evolutionary Cyclic Plasticity Material Parameters of 316 Stainless Steel: An Experimental \& Material Modeling Approach. Argonne National Laboratory Report ANL/LWRS-14/1 (http://www.osti.gov/scitech/biblio/1168233).

27. Dassault Systèmes (2014). ABAQUS 6.13 User Manual.

28. Shah, V. N., \& MacDonald, P. E. (1993). Aging and Life Extension of Major Light Water Reactor Components. Elsevier Science.

29. Schulz, T. L. (2006). Westinghouse AP1000 advanced passive plant. Nuclear Engineering and Design, 236(14), 1547-1557. 
30. Cummins, W. E., Corletti, M. M., \& Schulz, T. L. (2003). Westinghouse AP1000 advanced passive plant. In Proceedings of ICAPP, Vol. 3, pp. 4-7.

31. Westinghouse Electric (2000). Westinghouse AP600 Design Control Document. US-NRC Publication, ML003691016 (http://pbadupws.nrc.gov/docs/ML0036/ML003691016.html).

32. Westinghouse Electric (2011). Westinghouse AP1000 Design Control Document. US-NRC Publication, ML11171A500 (http://pbadupws.nrc.gov/docs/ML1117/ML11171A500.html).

33. Dorner, H., \& Michel, E. (1976). "Reactor pressure vessel support arrangement." U.S. Patent No. 3,947,322. Washington, DC: U.S. Patent and Trademark Office.

34. Desmarchais, W. E. (1971). "Reactor vessel supports." U.S. Patent No. 3,583,429. Washington, DC: U.S. Patent and Trademark Office.

35. International Atomic Energy Agency (2005). Natural Circulation in Water Cooled Nuclear Power Plants Phenomena, Models and Methodology for System Reliability Assessments. International Atomic Energy Agency Report ISEA-TECHDOC-1474.

36. Campbell, D. A. (1972). System for determining leakage inside a reactor containment. U.S. Patent 3,644,172.

37. Sengers, J. V., Watson, J. T. R., Basu, R. S., Kamgar-Parsi, B., \& Hendricks, R. C. (1984). Representative equations for the thermal conductivity of water substance. Journal of Physical and Chemical Reference Data, 13(3), 893-933.

38. American Society of Mechanical Engineers (2013). ASME Boiler and Pressure Vessel Code, section III \& section VIII.

39. Mohanty, S., Soppet, W. K., Majumdar, S., and Natesan, K., "Environmental Effect on Evolutionary Cyclic Plasticity Material Parameters of 316 Stainless Steel: An Experimental \& Material Modeling Approach," ANL/LWRS-14/1, http://www.osti.gov/scitech/biblio/1168233 (September 2014).

40. Mohanty, S., Soppet, W. K., Majumdar, S. and Natesan, K., "Pressurized Water Reactor Environment Effect on 316 Stainless Steel Stress Hardening/Softening: An Experimental Study," Proceedings of the ASME Pressure Vessels and Piping Conference, Paper No. PVP2015-45694 (2015).

41. Mohanty, S., Soppet, W. K., Majumdar, S., and Natesan, K., "Effect of Pressurized Water Reactor Environment on Material Parameters of 316 Stainless Steel: A Cyclic Plasticity Based Evolutionary Material Modeling Approach" Proceedings of the ASME Pressure Vessels and Piping Conference, Paper No. PVP201545701 (2015). 